Board of Governors of the Federal Reserve System

International Finance Discussion Papers

Number 1311

March 2021

\title{
Dynamic Econometrics in Action: A Biography of David F. Hendry
}

Neil R. Ericsson

Please cite this paper as:

Ericsson, Neil R. (2021). "Dynamic Econometrics in Action: A Biography of David F. Hendry," International Finance Discussion Papers 1311. Washington: Board of Governors of the Federal Reserve System, https://doi.org/10.17016/IFDP.2021.1311.

NOTE: International Finance Discussion Papers (IFDPs) are preliminary materials circulated to stimulate discussion and critical comment. The analysis and conclusions set forth are those of the authors and do not indicate concurrence by other members of the research staff or the Board of Governors. References in publications to the International Finance Discussion Papers Series (other than acknowledgement) should be cleared with the author(s) to protect the tentative character of these papers. Recent IFDPs are available on the Web at www.federalreserve.gov/pubs/ifdp/. This paper can be downloaded without charge from the Social Science Research Network electronic library at www.ssrn.com. 


\title{
DYNAMIC ECONOMETRICS IN ACTION: A BIOGRAPHY OF DAVID F. HENDRY
}

\author{
Neil R. Ericsson*
}

March 2021

\begin{abstract}
David Hendry has made - and continues to make - pivotal contributions to the econometrics of empirical economic modeling, economic forecasting, econometrics software, substantive empirical economic model design, and economic policy. This paper reviews his contributions by topic, emphasizing the overlaps between different strands in his research and the importance of real-world problems in motivating that research.

Keywords: cointegration, consumers' expenditure, dynamic specification, equilibrium correction, forecasting, machine learning, model evaluation, money demand, PcGive, structural breaks.
\end{abstract}

JEL classifications: C52, C53.

\footnotetext{
${ }^{*}$ Forthcoming as a chapter in Robert A. Cord (ed.) The Palgrave Companion to Oxford Economics, Palgrave Macmillan. The author is a staff economist in the Division of International Finance, Board of Governors of the Federal Reserve System, Washington, D.C. 20551 U.S.A. (ericsson@frb.gov); a Research Professor of Economics in the Department of Economics and a member of the H. O. Stekler Research Program on Forecasting, The George Washington University, Washington, D.C. 20052 U.S.A.; and an Adjunct Professor at the Paul H. Nitze School of Advanced International Studies (SAIS), Johns Hopkins University, Washington, D.C. 20036 U.S.A. The views in this paper are solely the responsibility of the author and should not be interpreted as reflecting the views of the Board of Governors of the Federal Reserve System or of any other person associated with the Federal Reserve System. The author is grateful to Cambridge University Press and Elsevier for permission to draw on material in Ericsson (2004, 2017), and to Jennifer Castle, Mike Clements, Robert Cord, David Hendry, Fred Joutz, Jaime Marquez, Andrew Martinez, and Tara Sinclair for helpful comments and suggestions.
} 


\section{Introduction}

David Hendry has made - and continues to make - pivotal contributions to the econometrics of empirical economic modeling, economic forecasting, econometrics software, substantive empirical economic model design, and economic policy. This paper reviews his contributions by topic, emphasizing the overlaps between different strands in his research and the importance of real-world problems in motivating that research.

David Forbes Hendry was born of Scottish parents on March 6, 1944 in Nottingham, England, where his parents were temporarily relocated for the war effort. After an unpromising start in Glasgow schools, David obtained an M.A. in economics with first class honors from the University of Aberdeen in 1966. He then went to the London School of Economics (LSE) and completed an MSc (with distinction) in econometrics and mathematical economics in 1967 and a PhD in economics in 1970 under Denis Sargan. His doctoral thesis, The Estimation of Economic Models with Autoregressive Errors, provided intellectual seeds for his future research on the development of an integrated approach to modeling economic time series. David was appointed to a lectureship at the LSE while finishing his thesis and to a professorship at the LSE in 1977.

In 1982, David moved to the University of Oxford as a Professor of Economics and a Fellow of Nuffield College. At Oxford, he has also been Acting Director for the Institute of Economics and Statistics (1982-1984), Leverhulme Personal Research Professor of Economics (1995-2000), ESRC Professorial Research Fellow (2003-2006), and chair of the Department of Economics (2001-2007). He is currently the Director of the program Economic Modelling (EMoD; Institute for New Economic Thinking at the Oxford Martin School, 2010-) and the Co-director of the program Climate Econometrics (2015-). He also helped design the university's Resource Allocation Model.

Much of David's research has focused on constructing a unified methodological approach to empirical modeling of economic time series. His 1995 book, Dynamic Econometrics, is a milestone on that path. General-to-specific modeling is an important aspect of this empirical methodology, which has become commonly known as the "LSE" or "Hendry" approach. David is widely recognized as the most vocal advocate and ardent contributor to this methodology. His research also has aimed to make this methodology widely available and easy to implement, both through publicly available econometrics software packages that embed the methodology (notably, PcGive and OxMetrics) and by substantive empirical applications of the methodology. As highlighted in many of his papers, David's interest in methodology is driven by a passion for understanding how the economy works and, specifically, how best to carry out economic policy in practice.

David's research has many strands. They include deriving and analyzing methods of estimation and inference for nonstationary time series; developing Monte Carlo methods for investigating small-sample properties of econometric techniques; exploring alternative modeling strategies and empirical methodologies; analyzing concepts and criteria for viable empirical modeling of time series; developing software for econometric analysis, culminating in model selection procedures utilizing machine learning; 
evaluating these developments in simulation studies and in empirical investigations of consumer expenditure, money demand, inflation, and the housing and mortgage markets; and re-assessing the history of econometric thought.

Over the last three decades, and in tandem with many of his developments in model design, David has reassessed the empirical and theoretical literature on forecasting, leading to new paradigms for generating and interpreting economic forecasts. He developed a taxonomy of forecast errors and a theory of unpredictability that have yielded valuable insights into the nature of forecasting. He has also provided new perspectives on many existing forecast techniques, including mean square forecast errors, add factors, leading indicators, pooling of forecasts, and multi-step estimation. In addition, David has developed new forecast tools, such as forecast encompassing; and he has improved existing ones, such as nowcasting and robustification to breaks.

David's enthusiasm for econometrics and economics permeates his teaching and makes his seminars notable. Throughout his career, he has promoted innovative uses of computers in teaching and, following the birth of the PC, he helped pioneer live empirical and Monte Carlo econometrics in the classroom and in seminars. To date, he has supervised over $40 \mathrm{PhD}$ theses, with numerous professional collaborations with his former doctoral students and other colleagues.

David has held many prominent appointments in professional bodies. He has served as president of the Royal Economic Society; editor of the Review of Economic Studies, Economic Journal, and Oxford Bulletin of Economics and Statistics; associate editor of Econometrica and the International Journal of Forecasting; president (Section F) of the British Association for the Advancement of Science; chairman of the UK's Research Assessment Exercise in economics; and special adviser to the House of Commons, both on monetary policy and on forecasting. He is a chartered statistician, co-founder of Econometrics Journal, and a fellow of the British Academy, the Royal Society of Edinburgh, and the Econometric Society. Among his many awards and honors, David has received the Guy Medal in Bronze from the Royal Statistical Society, eight honorary doctorates, a Lifetime Achievement Award from the ESRC, the Isaac Kerstenetzky Scholarly Achievement Award, and a knighthood from Her Majesty The Queen. The ISI lists him as one of the world's 200 most cited economists, and he is a Thomson Reuters Citation Laureate. In addition to his academic talents, David is an excellent chef and makes a great cup of cappuccino!

The remainder of this paper focuses on key contributions by David: the econometrics of empirical economic modeling (Section 2), econometrics software (Section 3), forecasting (Section 4), empirical analysis (Section 5), and Oxford connections (Section 6). 


\section{Economics, Econometrics, and Empirical Mod- eling}

The three golden rules of econometrics are test, test, and test; that all three rules are broken regularly in empirical applications is fortunately easily remedied. Hendry (1980, p. 403)

This quote from David's 1979 inaugural lecture at the London School of Economics is a common thread throughout his writings. He has authored or co-authored three books that are milestones in his contributions to the development of the econometrics for empirical economic modeling: Hendry (1995) Dynamic Econometrics, Banerjee, Dolado, Galbraith, and Hendry (1993) Co-integration, Error-correction, and the Econometric Analysis of Non-stationary Data, and Hendry and Doornik (2014) Empirical Model Discovery and Theory Evaluation. The titles to these books aptly serve as the titles to the subsections herein.

\subsection{Dynamic Econometrics}

Hendry (1995) Dynamic Econometrics provides a systematic framework for empirical modeling of economic data, focusing on economic time series. Drawing on a likelihood approach, this book lays out the economic and statistical underpinnings for empirical modeling, develops a typology of dynamic models, and ties the statistical theory of reduction to exogeneity, model evaluation, diagnostic testing, encompassing, and model design. The concept of a data generation process (DGP) is central to the theory of reduction, which implies that empirical models are derived from that DGP, rather than being autonomous constructs. This framework also allows a direct and unified

analysis of many traditionally ad hoc "problems" in econometrics, such as residual autocorrelation and heteroscedasticity, simultaneity, measurement errors, data mining, mis-specification, nonsense regressions, causality, expectations, structural breaks, and the Lucas critique. Constructively, Hendry (1995) provides a progressive research strategy for empirical econometric modeling that embodies both economic theory and data features, explicitly allowing for evolution in the data's structure and in economic theory itself. The empirical studies in Section 5 exemplify that progressive research strategy, and Hendry and Nielsen (2007) further develop the likelihood basis for this approach.

David's education set the stage for Dynamic Econometrics. David was motivated to study economics in Aberdeen and then in London because he saw unemployment, living standards, and equity as important issues. A scientific approach to their understanding required quantification, however, which led him to econometrics - and thence to econometric methodology - to determine what could be learnt from nonexperimental empirical evidence. In David's view, if econometrics could develop good models of economic reality, economic policy decisions could be significantly improved. Since policy requires causal links, economic theory plays a central role in model formulation. However, being highly abstract and simplified, economic theory could not be the sole basis for model formulation. Data and their analysis are crucial, with 
much variation in the data being due not to economic factors but to "special events" such as wars and major changes in policy, institutions, and legislation. Failure to account for these special events can obfuscate the role of economic forces in an empirical model.

Then, as now, the "conventional" approach to modeling was to write down the economic theory, collect variables with the same names (such as consumers' expenditure for consumption), develop mappings between the theory constructs and the observations, and then estimate the resulting equations. That approach often ignored institutional aspects and inter-agent heterogeneity, as well as inherent conflicts of interest between agents on different sides of the market. Nevertheless, economists often believed their theories to such an extent that they retained them, even when the theories were strongly rejected by the data.

David had learned that the conventional approach did not work well empirically, and that the straitjacket of that approach meant that one understood neither the data nor economic behavior. Instead, David tried a more data-based approach in which economic theory provided guidance rather than a complete structure-but that approach required developing concepts of model design and modeling strategy.

David's approach has four basic stages, beginning with an economic analysis to delineate key economic factors. The next stage embeds those factors in a general empirical model that also allows for other potential determinants and relevant special features. Then, the congruence of that general model is tested. Finally, the general model is simplified to a parsimonious undominated congruent final selection that encompasses the original model, thereby ensuring that all reductions (aka simplifications) are valid.

Chris Gilbert (1986) contrasted the conventional approach and David's approach, nicknaming the two as the "Average Economic Regression" (AER) and "Professor Hendry's Econometric Methodology". While the latter is often known as the "LSE" or "Hendry" approach, David is the first to acknowledge that many other individuals have also contributed to it, and that not all of those individuals have been at the LSE. Moreover, David himself has now spent most of his professional career at the University of Oxford, not the LSE.

When David began developing his approach, the first tractable cases for generalto-specific modeling were linear dynamic single equations, where a key issue was choice of appropriate lag length. That said, the general-to-specific principle applies to all econometric modeling, albeit with some complications for nonlinear settings; see Trivedi (1970) and Mizon (1977) for early empirical and theoretical contributions. Many other aspects followed, such as developing a taxonomy for model evaluation, orthogonalizing variables, and recommencing an analysis at the general model if a rejection occurs. Additional developments expanded this approach to system modeling, in which several (or even all) variables are treated as endogenous; see Hendry, Pagan, and Sargan (1984). Cointegration is easily analyzed as a reduction in this framework. So is encompassing of the VAR and determining whether a conditional model entails a valid reduction; cf. Mizon (1995) and Hendry (1997). David's empirical research embodies these features of model construction, as Section 5 details. Sections 2.3 and 3 discuss how his approach could be and was automated with machine learning, result- 
ing in the Autometrics feature of his and Jurgen Doornik's econometrics software package OxMetrics.

Dynamic Econometrics is the largest single project in David's professional career, and it had several false starts. In 1972, the large Italian public holding company IRI invited David Hendry and his former LSE classmate Pravin Trivedi to publish (in Italian) a set of lectures on dynamic modeling. In preparing those lectures, David and Pravin became concerned that conventional econometric approaches camouflaged mis-specification. Rather than resulting directly in a book, that process laid out a research agenda that included a general analysis of mis-specification, as in Hendry (1973, 1975); the unified treatment of econometric estimators, in Hendry (1976); and empirical model design, systematized in Hendry and Richard $(1982,1983)$ and Hendry (1983, 1987a).

In the 1980s, David visited Duke University on a regular basis and again attempted to write the book - this time with Bob Marshall and Jean-François Richard. Common factors, the theory of reduction, equilibrium correction, cointegration, encompassing, and exogeneity had already clarified the empirical analysis of individual equations; and powerful software with recursive estimators implemented the ideas.

Modeling complete systems raised new econometric and operational issues, so David and colleagues wrote the software package PcFiml, now part of OxMetrics; see Section 3. PcFiml ensures that system modeling begins with the unrestricted system, which is first checked for congruence. Modeling then reduces that system to a specific model thereof, tests over-identification, and encompasses the VAR; see Hendry, Neale, and Srba (1988), Hendry and Mizon (1993), and Doornik and Hendry (1994). This work paralleled and drew on concurrent developments in system cointegration by Søren Johansen, Katarina Juselius, and others in Copenhagen; see Johansen (1988, 1995), Johansen and Juselius (1990), and Juselius (2006). A daunting list of topics still remained, including general-to-specific modeling and diagnostic testing in systems, model reliability, and the role of inter-temporal optimization theory. Bob and JeanFrançois became more interested in auctions and experimental economics, so their co-authorship lapsed.

In the late 1980s, David circulated a first full draft of Dynamic Econometrics for comments, drawing extensively on help from Duo Qin and Carlo Favero. In Oxford, Duo had transcribed David's course lectures, themselves based on earlier draft chapters; and Carlo had drafted answers for the solved exercises. The final manuscript still took years more to complete.

As published, Dynamic Econometrics systematically covers a vast array of topics in econometric modeling and is almost 1,000 pages long, $6 \mathrm{~cm}$ thick, and heavy — which David has jokingly remarked makes it useful as a doorstop. David dedicated the book to his wife Evelyn and their daughter Vivien. The dedication was much more than perfunctory. Evelyn and Vivien not only facilitated time to work on ideas and visit collaborators, tolerated numerous discussions on econometrics, and corrected grammar; Vivien - a professional economist in her own right — worked through analyses and helped debug the software.

Dynamic Econometrics notably and deliberately omitted several major strands of David's research, as they were being published elsewhere. Those strands include 
Monte Carlo methodology, in Hendry (1984b) and Hendry, Neale, and Ericsson (1990); numerical issues and econometric software, in Hendry (1976), Hendry and Srba (1977, $1980)$, and Doornik and Hendry $(1992,1994)$; the history of econometrics, in Hendry and Morgan (1995); forecasting, in Clements and Hendry (1994, 1998b, 1999a); and cointegration in Hendry (1986a), Banerjee and Hendry (1992a), and Banerjee, Dolado, Galbraith, and Hendry (1993). On the last, Dynamic Econometrics lacks an extensive discussion of cointegration - a surprising omission, given David's interest in and major contributions to cointegration and equilibrium correction. However, because (co)integrated series can be reduced to stationarity, much of Dynamic Econometrics assumes stationarity, allowing Dynamic Econometrics to focus on modeling per se. Fittingly, the next subsection turns to cointegration.

\subsection{Co-integration, Error-correction, and the Econometric Analysis of Non-stationary Data}

David's early exposure to and understanding of error correction models - what are now called equilibrium correction models - lay the foundation for his contributions to cointegration, including the book by Banerjee, Dolado, Galbraith, and Hendry (1993) titled Co-integration, Error-correction, and the Econometric Analysis of Nonstationary Data. In the late 1960s and early 1970s, David had learned from the equilibrium correction models in Sargan (1964) how to model in differences and in levels of economic variables. A decade prior to Denis's paper, Bill Phillips (1954) of Phillips Curve fame and also at the LSE-had analyzed integral, proportional, and derivative control in formulating economic policy. Phillips's framework was also equilibrium correction. See also Smith (1926) and Mills (2011).

In the early 1970s, David, with James Davidson, began modeling UK consumers' expenditure in an equilibrium correction framework, eventually published as Davidson, Hendry, Srba, and Yeo (1978). At the same time, David and Gordon Anderson were modeling building societies, which are the British analogue of the US savings and loans associations. David discussed that work in his invited presentation at the August 1975 Toronto Econometric Society World Congress, showing that a system of equilibrium corrections could offset nonstationarity; see Hendry and Anderson (1977).

A major turning point came shortly thereafter during David's sabbatical in the United States. In November 1975, Chris Sims and the Minneapolis Fed sponsored a conference "New Methods in Business Cycle Research". In a presentation at the conference, Clive Granger critiqued the then-common poor econometrics of static regressions involving trending data, showing in particular that a high $R^{2}$ and a low Durbin-Watson statistic were diagnostic of mis-specification and indicative of a nonsense regression in the sense of Yule (1926). As an alternative, Clive proposed modeling differences of the variables, as advocated by Box and Jenkins (1970).

David was a discussant for Clive's presentation. While sympathetic to Clive's critique, David thought that the common factor interpretation of error autocorrelationin combination with equilibrium correction models - resolved the problem of nonsense regressions better than did differencing. Moreover, equilibrium correction models re- 
tained the economics. Clive's and David's presentations were subsequently published in the conference volume as Granger and Newbold (1977) and Hendry (1977).

At the conference, Clive was sceptical about relating differences to lagged levels, as in an equilibrium correction framework; and he doubted that the correction in levels could be stationary. Differences of the data did not have a unit root, whereas their lagged levels did. Investigating that issue helped Clive discover cointegration, with results published initially in Granger (1981, 1986), Granger and Weiss (1983), and Engle and Granger (1987). In his Nobel prize lecture, Clive gives an amusing account of his interchange with David at the Minneapolis conference.

A colleague, David Hendry, stated that the difference between a pair of integrated series could be stationary. My response was that it could be proved that he was wrong, but in attempting to do so, I showed that he was correct, and generalized it to cointegration, and proved the consequences such as the error-correction representation. Granger (2004, p. 363)

Clive's development of cointegration also resolved the debate between modeling in levels and modeling in differences, as David discussed in Hendry (2004).

In mid-1983, David visited Rob Engle and Clive Granger in San Diego and returned to Oxford all enthused about testing for cointegration. That rapidly resulted in one of the very first empirical applications of the Engle-Granger test for cointegration-Hendry and Ericsson (1983), later published as Hendry and Ericsson (1991a); see Section 5.3.

David's interest in cointegration led to an explosion of research activity: two special issues on cointegration for the Oxford Bulletin of Economics and Statistics, published as Hendry (1986a) and Banerjee and Hendry (1992a); a number of papers, including Banerjee, Dolado, Hendry, and Smith (1986), Hendry (1986b), Hendry and Neale (1988, 1991), Banerjee and Hendry (1992b), and Campos, Ericsson, and Hendry (1996); and the book by Banerjee, Dolado, Galbraith, and Hendry (1993). The last was prompted in part by innovative mathematical statistics that use Wiener processes to help describe the limiting distributions of unit-root processes, as developed by Phillips (1986, 1987), Stock (1987), Johansen (1988), Chan and Wei (1988), and others. David felt that the power and generality of that new approach would dominate the future of econometrics, especially since some proofs became easier, as with the forecast-error distributions in Clements and Hendry (1996b).

The key insight with cointegration, though, was conceptual. In the Granger representation theorem in Engle and Granger (1987), the data are integrated and cointegrated because the number of distinct equilibrium correction terms is less than the number of decision variables. Johansen (1988) formalized that property as reducedrank feedbacks of combinations of levels onto growth rates. Cointegration also explained and helped reinterpret many earlier results. For instance, in Sargan (1964), the equilibrium relationship involved real wages relative to productivity, with the measured disequilibrium determining future wage rates, given current inflation rates. Likewise, in Davidson, Hendry, Srba, and Yeo (1978), disequilibrium between consumers' expenditure and income affected future growth in expenditure; and Hendry (1980) showed that "nonsense regressions" could be both created and detected. 


\subsection{Empirical Model Discovery and Theory Evaluation}

Hendry (1995) lay the framework for empirical model evaluation and design, and Banerjee, Dolado, Galbraith, and Hendry (1993) provided the statistical framework for dealing with cointegration. However, the actual construction of a model by manually simplifying from general to simple was tedious, time-consuming, and fraught with error, not least because there often were many simplification paths to follow. David's initial empirical studies - of consumers' expenditure, money demand, and the mortgage and housing markets - highlighted those challenges and difficulties; see Section 5. A twofold serendipity for David led to remarkable breakthroughs in empirical modeling. First, general-to-specific modeling could be automated in computer software with machine learning. Second, the number of potential variables being considered could be more than the number of observations. Hendry and Doornik's (2014) book Empirical Model Discovery and Theory Evaluation provides the theoretical, statistical, computational, and empirical basis that integrates those breakthroughs.

The first serendipity occurred at a Carnegie-Rochester conference in November 1996. David was the discussant of Faust and Whiteman (1997), who critiqued the Hendry approach to modeling, with David's formal reply published as Hendry (1997). One of the conference participants was Kevin Hoover, who knew David from Oxford when he (Kevin) was writing his DPhil at Nuffield College in the early 1980s. Over drinks, Kevin expressed skepticism about general-to-specific modeling, with David pointing to the success of his and others' various empirical modeling efforts. After the conference, Kevin and his student Stephen Perez set out to scientifically challenge David's claim by constructing a computer-based simulacrum of what generalto-specific modelers did in practice, focusing on path search and diagnostic testing. Much to Kevin's surprise, the simulacrum worked well-phenomenally well in factand well beyond even David's own hopes and expectations; see Hoover and Perez (1999).

David immediately saw the potential of this computer-automated approach that employed machine learning. David and his colleague Hans-Martin Krolzig built on Kevin and Stephen's achievement, developing the econometrics package PcGets ("Gets" for general-to-specific). Subsequently, David and Jurgen Doornik embedded and enhanced that modeling approach directly in their econometrics package PcGive as the routine Autometrics; see Section 3 for further details.

The second serendipity arose through Jan Magnus and Mary Morgan's (1999) econometric modeling competition, in which they invited researchers to analyze two datasets, following different modeling approaches. One dataset was of the US demand for food from 1929 to 1989, building on Tobin's (1950) empirical analysis through 1948. Most investigators discarded the data for the interwar period and for the Second World War as being too difficult to model. For example, a standard demand model fitted over the whole sample delivered positive estimated price elasticities.

David was a late entrant in the competition, serving as discussant to Siegert (1999), who had analyzed the data acting "as if" he were David. In David's followup, published as Hendry (1999) and to be reprinted in Ericsson (2021), David aimed to replicate Siegert's and others' findings for the postwar subsample while actually using 
the whole sample. After all, more data should be better than less, if used in the right way. David thus estimated a given model over the whole sample, including indicator variables (one-off dummy variables for individual observations) for all observations up to the beginning of the postwar period. Several of those indicator variables were highly significant. Three were associated with a food program in the United States during the Great Depression. Unsurprisingly, the food program affected the demand for food. The other significant indicator variables were for years during the Second World War.

David then reversed the whole procedure, estimating the model over the whole sample but including indicators for the postwar period. That was equivalent to estimating the model over the first part of the sample. A few postwar indicators were marginally significant, as the corresponding Chow test revealed.

Finally, David estimated the model over the whole sample, including the indicators selected in the two subsample estimations. Of those indicators, only those for the food program and the Second World War were significant, and they had clear economic explanations. By including just those indicators, the whole sample could be adequately captured by a single model. The large data variability during the interwar period and the Second World War also greatly reduced the estimated economic parameters' standard errors, relative to those in the same model estimated on the postwar period alone.

In the process, David had included an indicator for every observation, albeit in two large blocks. Model selection could handle more potential variables than there are observations - something previously believed to be impossible, both theoretically and empirically. All indicators could be considered. The key was realizing: just not all of them at once.

There are precursors to this approach in the literature. For reference, the canonical case for this problem in model selection is impulse indicator saturation (IIS), in which the set of candidate explanatory variables includes a dummy variable for each observation. The solution to this canonical case is implicit in several existing techniques. For instance, as Salkever (1976) shows, the Chow (1960) statistic for testing predictive failure can be calculated by including zero-one indicator variables for all observations in the forecast period and then testing those indicators' joint significance. Recursive estimation is another example. Its "forward" version can be calculated by estimating the model, including an indicator variable for every observation in the latter part of the sample, and then sequentially removing the indicators, one indicator at a time. Both forward and backward versions of recursive estimation can be calculated in this fashion. Together, they require indicators for all observations in the sample and thus analyze as many potential variables as there are observations. Andrews's (1993) unknown breakpoint test and Bai and Perron's (1998) generalization thereon are also interpretable as specific algorithmic implementations of saturation techniques.

To understand IIS's properties, Hendry, Johansen, and Santos (2008) considered a stylized version of IIS with a split-half sample, similar to what David undertook empirically in Hendry (1999). Under the null hypothesis that there are no outliers or breaks in the DGP, IIS incurs only a small loss of efficiency. For example, for a sample size of 100 , on average one impulse indicator out of the 100 total would be significant 
at the $1 \%$ significance level. Because an impulse indicator merely removes one observation from the sample, the method is $99 \%$ efficient under the null hypothesis. IIS is almost costless, despite searching across 100 indicators.

Under the alternative hypothesis, IIS can detect multiple outliers and location shifts (aka structural breaks). Castle, Doornik, and Hendry (2012) demonstrate high power for multiple location shifts that are "large enough". Importantly, IIS can detect breaks that are near or at the ends of the sample. That circumvents an implicit shortcoming of the Andrews and Bai-Perron procedures. Johansen and Nielsen (2009) generalize the theory of IIS to include autoregressive distributed-lag models with or without unit roots and prove that IIS does not affect the rate of convergence of other parameter estimates to their population values.

IIS adds blocks of dummies to estimation and model selection. IIS can consider many blocks, thereby allowing many different alternatives to be considered. This feature of IIS has remarkable implications. Under the null hypothesis, an indicator for a given observation is significant only if it is discrepant. Its significance does not depend particularly on how or how often the indicators are split into blocks, provided that the blocks are large and that multiple search paths are explored.

The alternative hypothesis of multiple unmodeled breaks or outliers is equally important. For ease of discussion, assume two outliers. Detection of one outlier (the first, say) can be difficult unless the other outlier is accounted for. Failing to include that second outlier in the model induces a larger estimated error variance, making the first outlier appear less significant than it actually is. Hence, there is a need to include sufficient indicators to capture all actual outliers.

Hoover and Perez (1999) showed the advantages of multiple-path contracting searches that are guided by encompassing evaluations. Moreover, the block-search algorithm can be generalized to include candidate variables such as standard economic variables, and not just impulse indicators. Purely contracting searches are not always possible, but the principle of examining many large blocks remains. Blocks help avoid inadvertently eliminating variables that are correlated with already selected variables, and blocks help detect effects that are camouflaged by breaks.

Block searches allow selecting jointly across lag length, functional form, relevant variables, and breaks, even when doing so implies that the number of candidate variables is greater than the number of observations. Block searches can still be implemented, so long as the number of variables in each block is smaller than the sample size. Block searches can be iterated - and with changing composition - to allow many alternatives to be considered. Under the null, estimates of the parameters of interest are still relatively efficient. Under the alternative, it is particularly important to consider all of these complications jointly because they are likely to be connected. As with cointegration, proofs of distributional results involve additional mathematics, such as an iterated one-step approximation to the Huber-skip estimator; see Johansen and Nielsen (2013, 2016).

Other procedures tend to address just one or a few issues, rather than all of them at once. Nonparametric statistics can determine functional form but, in so doing, assume constant parameters, accurate measurements, and inclusion of all relevant variables. Robust statistics can tackle contaminated data but assume an otherwise 
correct specification. Step-wise regression and Lasso may easily detect a single omitted variable but can fail badly under multiple mis-specifications. Those techniques lack a mechanism that ensures capturing all relevant outliers and breaks. The blocksearch approach aims at considering all complications together. As Hendry and Johansen (2015) show, it can do so without distorting the distribution of the parameter estimates of a correct theory-specified model. In yet another moment of serendipity, David and Søren discovered this result while trying to prove something else.

Hendry and Doornik (2014) thus integrate the computer-automated model selection approach launched by Hoover and Perez (1999) and the impulse indicator saturation technique formulated in Hendry (1999), enhancing and generalizing both. Hendry and Doornik (2014) document that automated approaches such as Autometrics avoid the pernicious properties of many earlier approaches, which employed poor algorithms and inappropriate criteria for model selection and evaluation. Whether starting from a large model that nests the DGP or from a model that is the DGP itself, model search à l'Autometrics retains roughly the same relevant variables, and it obtains a controlled average number of irrelevant variables. Hendry (2015) and Castle and Hendry (2019) show at an intuitive level how these tools are accessible for empirical macro-econometric modeling of economic time series, illustrating with equations for wages, prices, unemployment, and money demand in the United Kingdom.

\section{Econometrics Software}

Operational econometric methods require computer software. David recognized this early on when writing his PhD thesis, so he wrote code in Fortran for the techniques that he was developing. David parlayed that code into a suite of mainframe software programs called AUTOREG, the most prominent being the single-equation package GIVE (for "Generalized Instrumental Variables Estimation"). GIVE served as a precursor to David's PC-based program PcGive. The programs in AUTOREG lay the framework for David and Jurgen Doornik's current software package OxMetrics, which includes PcGive. This section discusses how David's development of econometric software parallels and embodies his and others' innovations in econometric methodology, facilitated by extensive collaboration and by improvements in computing technology. Hendry and Doornik (1999) provide a brief history.

David had three reasons for developing econometrics software: to facilitate his own research, seeing as many techniques were not available in other packages; to ensure that other researchers did not have the excuse of unavailability; and for teaching. Early versions of GIVE demonstrated the computability of FIML for systems with high-order vector autoregressive errors and latent-variable structures. At the LSE, David and his research officer Frank Srba expanded David's initial version of AUTOREG to include new techniques, especially a rapidly expanding battery of model diagnostic (mis-specification) tests.

David saw diagnostic testing as a key aspect of empirical model building, functioning in much the same way that a medical doctor would run examinations and tests on patients to diagnose what was troubling them. Tests for predictive failure- 
along with numerous other diagnostics being developed at the time - were promptly implemented in AUTOREG; see Hendry and Srba $(1977,1980)$. At the time, few empirical economic models were subjected to much diagnostic scrutiny: it was typical to report just an $R^{2}$ and the Durbin-Watson statistic. In seminars and workshops, and in meetings at HM Treasury, the Bank of England, and elsewhere, David would question these untested assumptions in other authors' empirical models and volunteer to check out their models in GIVE, which quickly became known as Hendry's "model destruction program" (in the words of Meghnad Desai).

Shortly after moving to Oxford, David ported the mainframe program GIVE to a PC-based "PcGive", a menu-driven version initially on an IBM PC 8088 using a rudimentary MS-DOS Fortran compiler; see Hendry (1987b). That conversion took about four years, with his research officer Adrian Neale writing graphics in Assembler. One immediate benefit was a practical, graphical implementation of recursive estimation and testing procedures - a major leap forward for analyzing parameter constancy.

Jurgen Doornik then translated PcGive to $\mathrm{C}++$ and implemented it as a Windowsbased package with a front end (GiveWin), modules for single-equation and system estimation and testing (PcGive and PcFiml), Monte Carlo simulation (PcNaive), and specialized modules for modeling volatility, discrete choice, panels, ARFIMA, and X12ARIMA; see Doornik and Hendry (2001). Jurgen subsequently converted PcGive to his Ox language, enabling further additions by anyone writing Ox packages; see Doornik (2001).

Motivated by Hoover and Perez's (1999) results on computer-automated model selection, David and Hans-Martin Krolzig designed the PcGive-based econometrics software package PcGets, expanding on Hoover and Perez's tools for model selection; see Hendry and Krolzig (2001). PcGets's simulation properties confirmed many of the earlier methodological claims about general-to-specific modeling; and, through machine learning, PcGets provided significant time-savings to the researcher, especially for large problems; see Hendry and Krolzig (1999, 2005). David and Jurgen then embedded and enhanced PcGets's modeling approach in PcGive as the routine Autometrics; see Doornik and Hendry (2007) and Doornik (2008, 2009). Improvements to PcGive and the suite of OxMetrics packages continues unabated, as the most recent release in Doornik and Hendry (2018) testifies. The software manuals are substantial works in themselves, providing extensive discussion of the econometric and methodological underpinnings to the software's implementation.

PcGive embodies several important features for David, and for modelers generally. First, the software is flexible and accurate, with the latter checked by standard examples and by Monte Carlo. Second, it has rapidly incorporated new tests and estimators - sometimes before they appeared in print. Examples include Sargan's common-factor test, the system-based tests of parameter constancy from Hendry (1974) and Kiviet (1986) and their recursive equivalents, the Johansen (1988) reducedrank cointegration procedure, general-to-specific model selection, and impulse indicator saturation and its generalizations. Notably, other commercially available software packages are only starting to implement IIS, in spite of its power for detecting breaks and outliers. Third, while OxMetrics is interactive, it also generates editable batch code of user sessions, helping replication and collaboration - and combining the best 
of both batch and interactive worlds.

Empirical modeling still requires the economist's value added, especially through the choice of variables and the representation of the unrestricted model. The machinelearning algorithm Autometrics confirms the advantages of good economic analysis through excluding irrelevant effects and (especially) through including relevant ones. Excessive pre-simplification, as might be suggested by some economic theories, can lead to a badly mis-specified general specification with no good model choice from simplification. Fortunately, little power is lost from some over-specification with orthogonal regressors; and the empirical size remains close to the nominal one.

For David, automatic model selection is a new and powerful instrument for the social sciences, akin to the introduction of the microscope in the biological sciences. Already, PcGets and Autometrics have demonstrated remarkable performance across different (unknown) states of nature, with Monte Carlo data generating processes being found almost as often by commencing from a general model as from the DGP itself. Retention of relevant variables is close to the theoretical maximum, and elimination of irrelevant variables occurs at the rate set by the chosen significance level. The selected estimates have the appropriate reported standard errors, and they can be bias-corrected if desired, which also down-weights adventitiously significant coefficients. These results essentially resuscitate traditional econometrics, despite databased selection. Peter Phillips (1996) has made great strides in the automation of model selection using a related approach; see also Haldrup, Hendry, and van Dijk (2003).

\section{Forecasting}

A forecast is any statement about the future. Such statements may be well founded, or lack any sound basis; they may be accurate or inaccurate on any given occasion, or on average; precise or imprecise; and model-based or informal. ... Since [a forecast] is merely a statement about the future, anything can be forecast, ... Clements and Hendry (2002b, p. 2)

This quote from the introduction to David and Mike Clements's 2002 book A Companion to Economic Forecasting emphasizes just how widespread forecasts are - whether as ex ante or ex post forecasts, or as "projections", alternative simulations, or policy scenarios. As such, forecasts play key roles in economic decision-making by consumers, by firms, and by governments. David's own involvement in economic forecasting evolved from making forecasts (Section 4.1) through an understanding of the nature of forecasts (Section 4.2) to designing ways in which forecasts can be improved (Section 4.3).

\subsection{Making Forecasts}

David has made economic forecasts throughout his professional career. His early experiences in forecast failure motivated him to examine the roles of forecasts in 
economics, and thence to understand forecasts qua forecasts and seek out how to improve them.

David first became interested in forecasting in 1964 as an undergraduate at the University of Aberdeen. He was very much influenced by the empirical economic models of Klein (1950) and Tinbergen (1951), who had suggested the feasibility of forecasting future outcomes. In his undergraduate thesis, David estimated a regression model for annual UK consumers' expenditure given current income and lagged expenditure - painstakingly worked out on a mechanical calculator. Using the wholesample parameter estimates, he calculated a "forecast" of the last observation to see how close it was to the outcome - in effect, evaluating the last residual of his estimation period. The forecast and the outcome were reasonably close, but unsurprisingly so because the observation that was forecast was in the estimation sample, and hence the corresponding forecast error was included in the sum of squared residuals that least-square estimation minimized.

A few years later, when writing his PhD thesis under Denis Sargan at the LSE, David developed a small macro-model of the UK economy that included an equation for consumers' expenditure. David's forecasts from that model did not fare well. In late 1967, he calculated ex ante forecasts of consumers' expenditure for the next two quarters: 1968Q1 and 1968Q2. When actual expenditure was later reported by the Central Statistical Office, David's model had massive forecast failure and, in his own words, it took him years to understand why such forecast failure is commonplace.

That particular forecast failure arose from a change in economic policy. During 1968Q1, the Chancellor of the Exchequer (that is, the UK finance minister) threatened to increase Purchase Tax - essentially, a sales tax - if consumers did not "behave themselves" and spend less. Consumers responded by spending more, especially on durable goods. So, in the next quarter, the Chancellor duly increased Purchase Tax, and consumers' expenditure fell. David's model did not account for the Chancellor's policy threat, the policy's implementation, or consumers' responses to both. Consequently, the model's forecasts failed badly. Forecast failure notwithstanding, David's model was subsequently published in Hendry (1974), which included a new test for predictive failure that generalized Chow's (1960) single-equation predictive failure test to systems, albeit in a $\chi^{2}$ version rather than the $F$ version that Kiviet (1986) later developed.

Other economists were also evaluating forecasts from macro-models, and their contributions stimulated David's own thinking on the topic. Charles Nelson in particular wrote two influential papers on ex ante forecasts: Nelson (1972) and Cooper and Nelson (1975). Using methods proposed by Box and Jenkins (1970), Nelson and Cooper showed that forecasts from univariate time-series models could beat forecasts from large empirical economic models such as the FRB-MIT-PENN model. From an LSE perspective, such large models treated dynamics inadequately, often simply as autocorrelated errors in static equations. David suspected that, in a trade-off between mis-specified dynamics and omitted economics, models that included only dynamics could forecast better. Empirically, David found that simple dynamic models did indeed forecast better than static economic models, even though the latter embedded economic theory whereas the former did not. 
This debate on forecast performance motivated David to investigate the nature of predictive failure. Why did models built from even the best available economics using the latest econometrics and fairly good data not produce useful forecasts? In Hendry (1979), David attributed ex post predictive failure to model mis-specification. Chong and Hendry (1986) then developed forecast-encompassing statistics, a technique for comparing different models' forecasts. This approach is feasible even if the models themselves are unavailable, as is common with proprietary models and for judgmentally based forecasts. Hendry (1986d) looked at forecasting from dynamic systems, mainly to improve the power to test models.

The forecast failures documented in Hendry $(1974,1979)$ and elsewhere actually signalled a different source of forecasting problems with econometric models: unanticipated changes in the DGP. Those forecast failures also suggested that it was possible to develop a general theory of economic forecasting in which the forecasting model was mis-specified for a DGP that itself was nonconstant over time. These realizations came after a long hiatus, and they lead to the next section.

\subsection{Understanding Forecasts}

Until the early 1990s, David had viewed forecasting as an activity subsumed by model design. That perspective arose naturally from the taxonomy of information for empirical model evaluation and design in Hendry and Richard (1982), and from the framework for exogeneity in Engle, Hendry, and Richard (1983). While these developments were central to improvements in empirical modeling, they did hamper David's understanding of forecasting as a separate discipline in its own right. Moreover, the ubiquity of predictive failure was discouraging.

Policy rekindled David's interest in forecasting and led to major breakthroughs in the understanding of forecasts - particularly through the development of a taxonomy for the sources of forecast error. The catalyst was the 1991 enquiry by the UK Parliament's Treasury and Civil Service Committee into "Official Economic Forecasting"; see the Treasury and Civil Service Committee (1991a, 1991b). As a backdrop to the enquiry, forecasts by HM Treasury missed the 1987 boom in the UK economy and subsequently missed the sharp economic downturn in 1989, with the resulting policy mistakes combining to induce high inflation and high unemployment.

Evidence submitted to the parliamentary Committee included many forecasts from many forecasters and dozens of ex post forecast evaluations that tried to sort out why forecasts had gone wrong. Forecasts from different models frequently conflicted, and the underlying models often suffered forecast failure. As Makridakis and Hibon (2000) and Clements and Hendry (2001) later argued, those realities could not be explained within the standard paradigm that forecasts were the conditional expectations of the variables being forecast. Empirics dominated theory in the enquiry. In fact, there was almost no theory of economic forecasting presented. At the time, most theories of forecasting were from the physical sciences and statistical sciences. Those theories typically assumed data ergodicity and so were not necessarily relevant to economic forecasting, where intermittent structural breaks are a key data feature.

David submitted evidence on economic forecasting to the parliamentary Commit- 
tee. Preparation of his report - detailed in Hendry (1991) and to be published in Ericsson (2021) — led to a broader understanding of the subject. David subsequently produced a torrent of insightful evaluations of many existing forecast techniques, including error correction models and cointegration, mean square forecast errors, add factors, leading indicators, pooling of forecasts, multi-step estimation for forecasting, and forecast competitions; see Clements and Hendry (1998b, 1999a) in particular. David also developed a theory of forecasting, which included a taxonomy of forecast errors (initially sketched out in Hendry (1991)) and a theory of unpredictability with implications for parsimony, congruence, and aggregation; see Clements and Hendry (2005a), Hendry and Mizon (2014), and Hendry and Hubrich (2011). From that theory of forecasting, David was able to develop and refine tools such as intercept correction, robustification, and nowcasting to improve forecasts themselves; see Section 4.3.

David's renewed interest in forecasting resulted in a remarkable and continuing collaboration with his then DPhil student Mike Clements. Motivated by the encouraging developments in Hendry (1991), David and Mike sought to develop analytical foundations for understanding ex ante forecast failure when the economy is subject to structural breaks, and the forecasts are from mis-specified and inconsistently estimated models that are based on incorrect economic theories and selected from inaccurate data. Everything was allowed to be wrong, but the investigator did not know that.

Despite the generality of this framework, David and Mike derived many interesting results about economic forecasting, as shown in Clements and Hendry (1993) and Hendry and Clements (1994a, 1994b). The theory's empirical content matched the historical record, and it suggested how to improve forecasting methods. Estimation per se was not a key issue. The two important features in their framework were allowing for mis-specified models and incorporating structural change in the DGP. With that combination, causal variables need not beat non-causal variables at forecasting. In particular, extrapolative methods could win at forecasting, as shown in Clements and Hendry (1999b).

The implications are fundamental. Ex ante forecast failure should not be used to reject models. A model well-specified in-sample could forecast poorly - and worse than an extrapolative procedure so the debate between Box-Jenkins models and econometric models needed reinterpretation.

In this context, Clements and Hendry (1998a) brought to the fore the difference between equilibrium correction and error correction. The first induces cointegration, whereas in the latter the model adjusts to eliminate forecast errors. A cointegrated system - which has equilibrium correction - will forecast systematically badly when its equilibrium mean shifts, with the cointegrated system continuing to converge back to the old equilibrium. By contrast, devices such as random walks and exponentially weighted moving averages embody error correction. While an error correction model will temporarily mis-forecast when an equilibrium mean shifts, it will then adjust relative to the new equilibrium mean. Mike and David's insight explained why the Treasury's cointegrated system had performed so badly in the mid-1980s, following the sharp reduction in UK credit rationing. It also helped Clements and Hendry 
(1996a) demonstrate the advantageous property of intercept corrections to offset such shifts. Hendry and Ericsson (2001) and Castle, Clements, and Hendry (2019) offer highly intuitive nontechnical introductions to forecasting and their uses, challenges, and benefits. Clements and Hendry (2002a) gives a compendium.

David's initial collaborations with Mike Clements, however, examined mean square forecast errors (MSFEs), a standard tool for comparing forecasts from different models. Clements and Hendry $(1993,1995)$ questioned their value and generated considerable controversy - the discussants' published comments on Clements and Hendry (1993) are longer than the paper itself. Cointegration was the origin of these two papers.

At its inception in the early 1980s, cointegration had demonstrated many real advantages - in modeling, in economic understanding, and in interpretation. Engle and Yoo (1987) then discovered that imposing cointegration significantly improved forecasts in terms of MSFEs. This result seemed to show yet additional value from cointegration - in forecasting. Clements and Hendry (1995) replicated Engle and Yoo's Monte Carlo experiments and found that, to the contrary, imposing cointegration did not appear to reduce MSFEs. This discrepancy in results arose because Engle and Yoo (1987) had calculated MSFEs for the variables' levels whereas Clements and Hendry (1995) had calculated MSFEs for the cointegrating combination. Inadvertently, Clements and Hendry (1995) had discovered that data transformations affected MSFEs. Additionally, rankings across models often depended more on the choice of data transformation, and less on whether or not cointegration was imposed, or even whether the model included the equilibrium correction term.

Clements and Hendry (1993) formalized algebraically these properties of MSFEs. The ranking of different models' forecasts could alter, depending upon whether and how the variables being forecast were transformed. Ericsson (2008) illustrated this problem by comparing forecasts in levels and forecasts in differences for two models of crude oil spot prices. For forecasts of the level of oil prices, the MSFE for the first model was more than four times that for the second model. However, for forecasts of the change of oil prices, the MSFE for the first model was less than half that for the second model. Thus, a simple transformation of the variable being forecast altered the MSFE ranking of the models, with no change to the models, to the forecasts, or to the underlying data. Furthermore, the oil price example illustrated that, for a given model, the MSFE was not invariant to the transformation from levels to differences. Clements and Hendry (1993) showed that MSFEs lack robustness when the data are transformed, when forecasts are multivariate, and when forecasts are multi-step ahead. All three situations are common in economics.

Clements and Hendry (1993) also showed that useful comparison of MSFEs required highly restrictive assumptions about the forecasts - namely, that the forecasts must be of a single specific variable just one step ahead. Data transformations, multivariate forecasts, and multi-step-ahead forecasts are all outside that limited structure because they imply a vector of forecasts. Clements and Hendry (1993) discussed how the predictive likelihood generalizes the MSFE for a vector of forecasts. Moreover, predictive likelihood is the only direction-invariant measure, as it does not depend on nonsingular linear scale-preserving transformations of the system. Even so, predictive 
likelihood has not been used much for forecast evaluation. Wallis (1993) pioneered its use, but its practical implementation was hindered because its calculation seemed to require having sufficient observations on all the multi-step-ahead forecast errors in order to estimate their variance-covariance matrix. Results in Abadir, Distaso, and Žikeš (2014) encouraged David to revisit predictive likelihood in Hendry and Martinez (2017), where they show that one can evaluate multi-step-ahead system forecasts with relatively few forecast errors. Explicit loss functions also have come back into favor, as in Granger (2001) and Barendse and Patton (2019).

Because MSFEs are widely used for comparing forecasts, David and Mike became interested in the forecasting competitions organized by Spyros Makridakis, which at that time was the M3 competition, hosted by the International Journal of Forecasting. Many different time series were divided into subperiods, each of which was then forecast by many methods, albeit usually only one step ahead. Various evaluation criteria were applied to each forecasting device on each dataset to find which methods had the best ex post forecast performance as measured by the chosen criteria. Those methods with the best forecast performance then "won" the competition. Because parsimonious methods such as damped trend often did well, whereas less parsimonious methods such as econometric models often did poorly, Makridakis and Hibon (2000) concluded that parsimony was key to good forecast performance.

David could not understand why parsimony per se should make models do so well at forecasting. After all, the sample mean of a variable's level is parsimonious, but it is often a dreadful forecast of the variable's future values. To understand the empirical results in the M3 competition and, more generally, to help interpret the problems that arise in economic forecasting, David and Mike developed a general analytical framework that describes a taxonomy for forecast errors. Initially, David and Mike solved the taxonomy for vector autoregressive models and simple time-series models. More recently, David has considered open dynamic simultaneous systems and nonlinear formulations.

The taxonomy delineates all possible sources of forecast error-nine sources in total. These sources derive from the three components of a model:

(i) unobserved terms,

(ii) observed stochastic variables, and

(iii) deterministic terms.

The first component is what the model fails to explain, and it thus includes mismeasurement of the data at the forecast origin, omitted variables, and the innovation errors in the DGP. The second and third components characterize what is modeled, and they often correspond to the slope parameter and the equilibrium mean. Each of the model's three components is itself subject to three potential problems:

(a) estimation uncertainty,

(b) mis-specification, and

(c) change in the DGP's parameter values, leading to a $3 \times 3$ array of possibilities and implying nine sources of forecast error.

The taxonomy has immediate implications: the consequences of forecast error depend on the sources of forecast error; and the taxonomy allows deriving the effects of each source for a given forecasting device. For instance, the combination (iii) $+(\mathrm{c})$ 
is an out-of-sample structural break involving deterministic terms, as with a change in the equilibrium mean. For equilibrium correction models, that particular combination results in systematic mis-forecasting. That problem is fundamental, pernicious, and common in economic forecasting. Such predictive failure due to a location shift is easily detected because it induces forecast bias and increases the MSFE, noting that the MSFE includes the squared shift in the mean. Other sources of forecast error can deteriorate forecast performance as well, but they are often harder to detect and with more benign effects. If forecast errors arise from multiple sources, interactions between sources may also matter.

More generally, the taxonomy reveals which sources of forecast error most affect each forecasting method, thus clarifying why some methods out- or under-perform others, and when. For intermittent location shifts, all methods mis-forecast at the break. However, after the breakpoint, methods that are not robust to such breaks tend to make systematic forecast errors, whereas robust methods get the forecasts back on track; see Hendry and Doornik (1997).

The taxonomy also shows that rankings of forecasts should not depend particularly on the number of parameters in either the model or the DGP, whereas the rankings do depend on the robustness of the forecasting devices to structural breaks. The design of forecast competitions such as M3 happened to favor robust devices by having many short forecasting subperiods with intermittent location shifts in the data, thus giving the impression that parsimony per se was advantageous in forecasting. Clements and Hendry (2001) showed that many of the key empirical results in the M3 competition were derivable from the taxonomy of forecast errors. Clements and Hendry (1994, 1998b, 1999a, 2006) give comprehensive derivations and analyses of the taxonomy.

One major insight about forecasting came during a seminar in which David was explaining a very early version of the taxonomy. David noticed that the change in the slope coefficient $[(\mathrm{ii})+(\mathrm{c})$ above] was multiplied by the deviation of the data at the forecast origin from the data's equilibrium mean. Consequently, if forecasting happened to start when the data were in equilibrium, changes in the slope parameter would not affect the forecast errors. Indeed, if the mean of the data stayed constant and the forecast origin were accurately measured, forecasts would not be systematically biased - even if all the other problems were present. Conversely, out-of-sample location shifts would systematically bias the forecasts, even if the forecast model were the in-sample DGP itself. That realization in the middle of the seminar astonished David as much as the seminar participants!

Hendry and Mizon (2000a, 2000b) found additional implications of the taxonomy: the best explanatory model need not be the best for forecasting, and the best policy model could conceivably be different from both. Some structural breaks - such as shifts in equilibrium means - are inimical to forecasts from econometric models but not from robust forecasting devices, which themselves may well not explain behavior. However, such shifts need not affect the relevant policy derivatives. For example, the effect of interest rates on consumers' expenditure could be constant, despite a shift in the target level of savings due to (say) changed government provisions for health care in old age. After the shift, altering the interest rate still could have the expected policy effect, even though the econometric model mis-forecasted. Because 
econometric models can be robustified against such forecast failures, it may prove possible to use the same baseline causal econometric model for forecasting and for policy.

This analytical framework represents considerable progress in developing a general theory of forecasting. It does not assume how the model is estimated, how badly mis-specified it is, or what changes occur in the economy. Many aspects still need more research, though, including how to forecast breaks, how to best select forecasting models for realistic economic processes, and how to improve forecasts - the next topic.

\subsection{Improving Forecasts}

The taxonomy clarified the sources of predictive failure. The taxonomy also led to and formalized new techniques that robustify forecasts after structural breaks and that augment robust devices with information from economic models. Robustification led to research on nowcasting and, from a completely different route, impulse indicator saturation. Hendry (2006) develops and systematizes robustification methods, which include intercept correction, pooling, leading indicators, and differencing. These four tools and nowcasting serve as foci for discussing David's contributions to improving forecasts.

Intercept correction. In addition to investigating the many aspects of forecasting discussed in Section 4.2, David and Mike Clements re-examined the ubiquitous forecast tool known as "add factors". Add factors are now interpretable as a form of intercept correction and hence are a potentially useful method for robustifying forecasts against the effects of structural breaks. This interpretation contrasts with David's earlier harsh views on add factors, as one example illustrates. Peter Hooper was presenting forecast results on the Fed's Multi-country Model at a Fed workshop in 1985, and David was highly critical of Peter's adjustment of the forecasts with add factors. At the time, David remarked: "Why adjust forecasts if the model is good?". David's views on add factors have evolved enormously since then.

Some history helps put that evolution in perspective. Klein (1971) discussed that add factors might improve economic forecasting, but he gave no theory explaining why they might do so. There was no such theory at the time. Much later, David and Mike Clements realized that some types of add factors might mitigate forecast failure that was caused by location shifts at the start of the forecast period. Clements and Hendry (1996a) showed analytically and in practice how intercept correction could improve forecasts in the face of location shifts. Intercept correction differences the forecast error that would have occurred otherwise and thereby removes the original forecast error's systematic component. Consequently, intercept correction is a valuable tool in the face of location shifts.

Pooling. Combining or "pooling" forecasts provides another tool for robustifying forecasts. Bates and Granger (1969) proposed combining forecasts as a mechanism for improving forecast performance. Chong and Hendry (1986) later showed that pooling is unnecessary under the null of forecast encompassing but could improve forecasting when (e.g.) neither of two forecasts forecast-encompassed the other forecast. Bates 
and Granger provided the intuition: in that situation, each forecast model has information that the other model does not. Pooling combines the information in the models' forecasts. Bates and Granger did not address the question of whether pooling forecasts was better than utilizing the information from both models in a nesting model and generating forecasts from that model. Hendry and Clements (2004) showed that there was no unique answer. It can pay to pool forecasts in some situations and not in others.

Pooling is often viewed as being benign at worst, serving as insurance against bad forecasts by averaging across a range of forecasts. It does carry an important caveat, though: a single poor forecast can ruin the average. Imagine having a set of good models, along with one poisonous model. Averaging the forecast of the poisonous model with those of the good models can poison the pooled forecast. If the poisonous models are eliminated - through model selection, say - then averaging over the forecasts from just the remaining models may reduce the risk a little; see Hendry and Doornik (2014, p. 286).

In the literature, model averaging is often over all possible models that arise by either including or excluding the variables from a given set of explanatory variables. Most of those models are "poisonous" because they are distorted by omitted variables, unmodeled nonlinearities, intermittent location shifts, etc. One has to be careful which forecasts one averages across, and how that averaging is carried out. In their submission to the recent M4 forecast competition, Doornik, Castle, and Hendry (2020a) designed pooled forecasts with computer-automated model selection, aiming to embody key features learned from the taxonomy.

Forecasts from different models may also be of value in themselves. Divergence of different models' forecasts can indicate breaks that are occurring and hence can serve as "canaries in the mine". The Bank of England has used a suite of models in this manner, as Hatch (2001) discusses in Hendry and Ericsson (2001). When models are sufficiently different, they need not all be affected in the same way by a major unanticipated shift. Including robust forecasting devices in the suite of models can help, too. Robust devices are not affected systematically once the breakpoint is past, although they will still mis-forecast as the break hits.

Leading indicators. Leading indicators are yet another tool aimed at improving forecasts. Emerson and Hendry (1996) found that the variables selected as leading indicators changed all too often, suggesting that they did not lead for very long. Also, picking leading indicators by maximum in-sample correlation was unreliable. Emerson and Hendry (1996) concluded that using only leading indicators for economic forecasting was not a fruitful route to pursue.

That said, leading indicators could have some role in forecasting. For instance, a cointegrated system can be written as a set of differenced variables that are explained by lagged cointegrating combinations and lagged differenced variables. That system is interpretable as a system of leading indicators because its endogenous variables depend on past outcomes. Also, higher frequency information may improve forecasting performance, with that information acting as a leading indicator. Moreover, leading indicators may help predict turning points and breaks, as in Birchenhall, Jessen, 
Osborn, and Simpson (1999).

Differencing. Hendry (2006) shows that predictive failure is an inherent issue for econometric models and that differencing is a natural solution for robustifying those models' forecasts. To put differencing in context, Hendry notes that virtually all standard economic models are equilibrium correction models, including dynamic stochastic general equilibrium (DSGE) models, New Keynesian Phillips Curve models, structural vector autoregressions, and so-called error correction models. When the equilibrium mean alters, the model's equilibrium correction term pushes the model's forecasts back towards the old equilibrium - not the new one -inducing the sort of systematic predictive failure that is often seen in practice. Intercept correctionand hence differencing - can robustify the forecast of an equilibrium correction model because it serves as a good proxy for such shifts in the equilibrium. Hendry (2006) formalizes this. Castle, Clements, and Hendry (2013, 2015) illustrate it empirically with an assessment of robustified US GDP forecasts.

The taxonomy of forecast errors also provides insights on why differencing a model robustifies the model's forecasts. From the taxonomy, few things can go wrong in forecasting a variable if the forecasting model for the second difference of that variable has no parameters and no deterministic terms, thereby eliminating the sources of forecast error in (iii) and (a) above. If the data do not accelerate, the second difference of the variable being forecast has a mean of zero, implying that the first difference of the current-dated variable (or the current growth rate) is an unconditionally unbiased forecast for its future value. Because that current growth rate is the current value and not the future one, such a "forecast" device never really forecasts. However, the current growth rate will be close to the future growth rate in the absence of acceleration.

The first difference of the dependent variable has another interpretation as well: it is a single measure that aggregates almost all the information needed in forecasting its future value. The explanation requires a slight digression. In David's view, economists build congruent, encompassing, cointegrated models to test theories, understand the economy, and conduct policy analysis. These models also need to account for breaks and other nonstationarities. For forecasting, though, these models can be differenced to eliminate deterministic terms such as intercepts and location shifts. Doing so introduces the current growth rate in the model for forecasting the future growth rate; and the current growth rate depends on the cointegrating relationship as a feedback term. This new system thus retains the economics and the policy-relevant causal information that underlie the original model. And, differencing the model introduces the first difference of the model's other economic variables.

Moreover, because the current growth rate itself is generated by the DGP, it necessarily includes relevant variables for forecasting the future growth rate. By contrast, a model of the current growth rate is a simplification of the DGP and need not include the relevant variables that determine the current growth rate. When forecasting, there also is no need to disentangle the DGP's individual components that enter the current growth rate - unlike when modeling or for policy analysis. The data themselves provide the basis for forecasting. As a practical implication, differencing 
creates a system that is robust after location shifts because the current growth rate includes all stochastic and deterministic shifts, and also any variables omitted from the forecast model. Moreover, use of the current growth rate to forecast the future growth rate obviates the need to estimate model parameters.

Hendry (2006) derives yet another, related interpretation of the current growth rate, as arises from the standard representation of the vector equilibrium correction model ( $\mathrm{VEqCM})$. In the simplest $\mathrm{VEqCM}$, the future growth rate of the dependent variable is forecast by its mean growth rate (the VEqCM's intercept) and the current disequilibrium (the deviation of the cointegration vector from the equilibrium mean). Both the mean growth rate and the current disequilibrium employ full-sample estimates of the model's parameters. In the differenced VEqCM (or DVEqCM), however, the mean growth rate is estimated by the current growth rate, and the disequilibrium is estimated by the deviation in the cointegrating relation from its previous value. Both terms in the DVEqCM are estimates that use only current-dated observed growth rates, although the cointegrating coefficients themselves need to be estimated with a longer sample.

Forecasts from the VEqCM itself use fixed values of two key $\mathrm{VEqCM}$ componentsthe mean growth rate and the equilibrium mean - shifts in which can cause forecast failure. By contrast, forecasts from the DVEqCM use the current period's observations to estimate those key components and so may be more relevant for forecasting than using the full historical sample.

This approach generates a class of "data-based" forecasting devices that could utilize a single observation (as in the $\mathrm{DVEqCM}$ ), a subset of observations (as in rolling regressions), or the full sample (as in the $\mathrm{VEqCM}$ ); see Martinez, Castle, and Hendry (2021). The choice of sample highlights a trade-off between precision in estimation and rapid adaptation. As harbingers to these developments in forecasting, Hendry and Ericsson (1991b) and Campos and Ericsson (1999) formulated such databased predictors in empirical modeling. Other similar approaches, such as in Phillips (1995), adapt the forecasts to location shifts through automated variable reselection and parameter estimate updating. Eitrheim, Husebø, and Nymoen (1999) empirically document implications of the taxonomy by comparing real-world forecasts from Norges Bank's macro-model RIMINI with forecasts from simple robust devices, finding that the latter often won at four quarters ahead but lost out at a longer forecast horizon; see also Bårdsen, Eitrheim, Jansen, and Nymoen (2005).

Nowcasting. The taxonomy of forecast errors also has implications for nowcasting. David and Mike Clements started thinking about nowcasting in a more structured way when they were consulting for the UK Statistics Commission and evaluating how the UK's Office for National Statistics calculated its flash estimates of the national accounts; see Clements and Hendry (2003). Nowcasting can imply measurement errors of the forecast origin, i.e., the combination (i)+(a) from Section 4.2 above. Sometimes, those errors are systematic and large, as with official economic statistics during the 2008 financial crisis and the more recent COVID-19 pandemic. Improved methods of nowcasting can help reduce real-time forecast problems that arise from mis-measuring the forecast origin. 
Large data revisions during the financial crisis and COVID-19 pandemic are not surprising in light of the methods used to produce flash estimates. For example, in the United States and the United Kingdom, a flash (or "advance") estimate of quarterly GDP growth is released about a month after the quarter's end, and that flash estimate is derived in part from many disaggregate components. Observations on some disaggregate components become available too late for inclusion in the flash estimate, so those missing components are "infilled", based on interpolation models such as Holt-Winters (a form of exponential smoothing).

Such infilling can work reasonably well during times of steady and uniform growth across the economy. However, sudden changes in data behavior - as occurred during the financial crisis - can make interpolation methods inappropriate. They led to flash estimates of aggregate economic growth that were systematically above the final data in the downturn and systematically below the data in the upturn - often by several percentage points per annum; see Ericsson (2017). In 2008, these mis-measurements made it difficult for policymakers to ascertain the timing and extent of the crisis, as Stekler and Symington (2016) and Ericsson (2016) discuss.

Systematic errors such as these have led to proposed improvements in nowcasting, as documented in Mazzi and Ladiray (2017). The taxonomy delineates what does and what does not cause forecast failure and so has direct implications for nowcasting; see Castle, Hendry, and Kitov (2017). When a statistical agency estimates (say) GDP growth from a set of disaggregate components, the agency could check whether previous forecasts of those components are close to their now known outcomes. If they are not, a location shift may be responsible, so any missing disaggregates could be infilled, taking into account information about the recent break. Considerable contemporaneous information is available for nowcasting, including surveys, Google Trends, mobile phone data, prediction markets, and previous historically similar episodes. All could be used to improve the accuracy of forecast-origin estimates. Automatic model selection can help do so, as by building forecasting models of the disaggregated series. An alternative approach is to summarize the information from large numbers of variables by using principal components or factors: see Forni, Hallin, Lippi, and Reichlin (2001), Artis, Banerjee, and Marcellino (2005), Stock and Watson (2011), and Castle, Clements, and Hendry (2013). Regardless, nowcasts that utilize such additional information could be created before the end of the reference period, thereby reducing the delay with which flash estimates appear.

The coronavirus pandemic poses a global challenge - medically, socially, politically, and economically. To better inform decision-making, Jennie Castle, Jurgen Doornik, and David Hendry have been generating short-term (one-week-ahead) forecasts for confirmed cases and deaths from COVID-19; see Castle, Doornik, and Hendry (2020a) and Doornik, Castle, and Hendry (2020b, 2021). Jennie, Jurgen, and David select their forecast models by Autometrics, incorporating generalizations of impulse indicator saturation. In addition, Castle, Doornik, and Hendry (2020b) have been making medium-term (multi-week) forecasts from models utilizing path indicator saturation (PathIS) - a new saturation technique that saturates across paths, similar to the designer breaks in Pretis, Schneider, Smerdon, and Hendry (2016). Both the short-term 
and medium-term forecasts combine key elements of David's contributions in Sections 2-4, including model design through machine learning with diagnostic testing and saturation techniques, and forecast design through robustification in light of the forecast taxonomy. Notably, these forecasts perform well relative to some standard epidemiological models.

In retrospect, David's attitude toward economic forecasting - and the profession's attitude as well - has shifted significantly over the last three decades, and for the better. Many top econometricians are now involved in the theory of forecasting, including Frank Diebold, Hashem Pesaran, Peter Phillips, Lucrezia Reichlin, Jim Stock, Timo Teräsvirta, Ken Wallis, and Mark Watson. Their technical expertise as well as their practical forecasting experience is invaluable in furthering the field. As the taxonomy illustrated, mathematical treatment can help understand economic forecasts, with key developments summarized in the books by Hendry and Ericsson (2001), Clements and Hendry (2002a, 2011), and Elliott, Granger, and Timmermann (2006).

\section{Empirical Analysis}

Empirical analysis often motivated David's new developments in econometric methodology, as when Ericsson, Hendry, and Prestwich (1998) were modeling UK money demand on an extended dataset. That analysis led to a formal treatment of expansions of information sets, itself laying the groundwork for saturation techniques. Conversely, David would also almost immediately apply new methodological developments to ongoing empirical analyses, as when incorporating the Engle-Granger cointegration test into Hendry and Ericsson's (1983) empirical analysis of UK money demand. While David's empirical analyses cover many aspects of the economy for many countries and regions, five modeling endeavors stand out: housing and mortgage markets, consumers' expenditure, money demand, television advertising, and climate change. This section examines those endeavors.

\subsection{Mortgage and Housing Markets}

David's professional interest in UK housing and mortgage markets began in the early 1970s, when he and Gordon Anderson were modeling building societies - the British analogue of US savings and loans associations. Hendry and Anderson (1977) nested the long-run solutions of existing empirical equations, using a formulation related to Sargan (1964), although the link to Denis's work was only clarified much later in Anderson and Hendry (1984).

David's interest in the housing market arose from a forecasting puzzle. During 1972, UK house prices rose dramatically in response to a major increase in mortgage lending by building societies. David later checked how well his house-price model would have forecast through that period. When forecasting a few quarters after the then largest-ever increase in UK house prices, the model predicted a fall in prices, while prices actually continued to rise substantially. Nevertheless, coefficients esti- 
mated over the pre-forecast period were almost identical to those estimated over the whole sample, and the whole-sample residuals were homoscedastic, so there appeared to be little evidence of parameter nonconstancy.

David finally resolved this conundrum over a decade later, when he and Mike Clements were developing the general theory of forecasting. That theory distinguishes between "internal breaks" (shifts in the model's parameters) and "external breaks" (shifts in the unmodeled included variables). A change in multicollinearity among the model's variables leaves estimated coefficients almost unchanged but can greatly increase MSFEs, contrasting with the irrelevance of multicollinearity to forecast uncertainty when multicollinearity is constant. This problem with multicollinearity cannot be solved by orthogonalizing the model's variables or by eliminating relevant multicollinear variables. The latter can lead to even worse forecasts. However, updating parameter estimates with new data can reduce MSFEs. For UK house prices, the correlations of mortgage lending with disposable income, interest rates, and inflation altered markedly when mortgage lending itself increased. Despite the accrual of more information from changes in multicollinearity, the MSFE also increased, in line with the general theory of forecasting.

Model nonlinearities proved central to explaining house-price bubbles. Through David's interest in the natural sciences, he had learned that Van der Pol's cubic differential equation could describe heartbeats, and that heartbeats could manifest sudden surges. Changes in UK house prices seemed rather like heartbeats so, in his model, he included the cube of the excess demand for housing, as represented by the cube of lagged house-price inflation. As Hendry (1984a) showed, the cube was significant. The formulation had difficulties, though. It predicted some large jumps in house prices that did not materialize. It also implied that large changes in house prices were explosive. In practice, though, once the market was far from equilibrium, excessively high or low house-price-to-income ratios drove the market back towards equilibrium, as followed after the UK housing bubble in the late 1980s. Richard and Zhang (1996) improved on David's nonlinear formulation by using a cubic in the observed deviation from the long-run equilibrium rather than the cube of house-price inflation.

In related research, Ericsson and Hendry (1985) showed that the price of new housing piggybacked on the price of existing houses in an equilibrium correction framework that also accounted for construction costs, housing units still under construction, and the cost of financing. Hendry (1986c) modeled the construction sector, focusing on the determination of starts and completions of houses.

\subsection{Consumers' Expenditure}

In modeling UK consumers' expenditure, David adopted a modeling approach similar to that in Hendry and Anderson (1977) by seeking a consumption function that served to interpret the equations from the major UK macro-models and explain why their proprietors had picked their particular specifications. The resulting paperDavidson, Hendry, Srba, and Yeo (1978), often referred to as "DHSY" - has become one of David's most cited papers. DHSY adopted a "detective story" approach, 
using a nesting model for the different models' variables, valid for both seasonally adjusted and unadjusted data, and with up to five lags on all the variables to capture dynamics. Reformulation of that nesting model delivered an equation that Hendry and von Ungern-Sternberg (1981) later reinterpreted in light of Phillips $(1954,1957)$ and called an error correction model. Under error correction, if consumers made an error relative to their plan by over-spending in a given quarter, they would later correct that error.

Some historical background helps illuminate DHSY's approach. David first had access to computer graphics in the early 1970s, and he was astonished by the graphs of real UK consumers' expenditure and income. Expenditure manifested vast seasonality, with double-digit percentage changes between quarters, whereas income had virtually no seasonality. Those seasonal patterns meant that expenditure was much more volatile than income on a quarter-to-quarter basis. Two implications followed. First, it would not work to fit a model with first-order lags (as David had done in Hendry (1974)) and hope that seasonal dummies plus the slight seasonality in income would explain the seasonality in expenditure. Second, the general class of consumption-smoothing theories such as the permanent-income and life-cycle hypotheses seemed mis-focused. Consumers were inducing volatility into the economy by large inter-quarter shifts in their expenditure, so the business sector must be a stabilizing influence. Moreover, as discussed in Section 4.1, the equation for consumers' expenditure in Hendry (1974) had dramatically mis-forecast the first two quarters of 1968, suggesting the need for respecification.

In developing their own model, DHSY examined several ingredients that were necessary to explain other modelers' model selections: their modeling approaches, data measurements, seasonal adjustment procedures, choice of estimators, maximum lag lengths, and mis-specification tests. DHSY first standardized on unadjusted data and replicated models on that. While seasonal filters leave a model invariant when the model is known, they can distort the lag patterns if the model is data-based. DHSY then investigated both least squares and instrumental variables estimation but found little difference. Few of the then reported evaluation statistics were valid for dynamic models, so such tests could mislead. Most extant models had a maximum lag of one, and they had short-run marginal propensities to consume that seemed too small to reflect agent behavior. DHSY tried many blind alleys (including measurement errors) to explain these low marginal propensities to consume. DHSY then showed that equilibrium correction explained the low marginal propensities to consume by the induced biases in partial adjustment models. DHSY designed a nesting model, which explained all the previous findings, but with the puzzle that it simplified to a differenced specification, with no long-run term in the levels of the variables. Resolving that conundrum led to the equilibrium correction mechanism. DHSY's "Sherlock Holmes" approach was extremely time-consuming and was rarely repeated subsequently; but it did stimulate research into encompassing, i.e., trying to explain other models' results from a given model's perspective.

Even with DHSY's wide-ranging and highly systematic modeling approach, a significant model reformulation occurred just before publication. An earlier version of DHSY's model explained real consumers' expenditure given real income, and that 
model significantly over-predicted expenditure through the 1973-1974 oil crisis. Angus Deaton (1977) had just established a role for inflation in a consumption function if agents were uncertain as to whether relative prices or absolute prices were changing. Deaton's formulation suggested adding inflation and its lags to that earlier DHSY specification. Doing so explained the over-prediction. This result was the opposite to what some other economic theories suggested - namely, that high inflation should induce pre-emptive spending because inflation is an opportunity cost of holding money. Inflation did not reflect money illusion. Rather, it implied the erosion of the real value of liquid assets. Consumers did not treat the nominal component of after-tax interest as income, whereas the UK government's statistical office did, and so disposable income was being mis-measured. Adding inflation to DHSY's equation corrected that.

DHSY made enormous advances empirically and methodologically. However, it did miss some key issues, including the equivalence of equilibrium correction models and cointegration (discussed in Section 2.2); the implications of seasonality in the data for annual differences in the model; the role of liquid assets in determining consumers' expenditure; and the insights of Phillips $(1954,1957)$ on proportional, integral, and derivative control rules. Collaboration with Thomas von Ungern-Sternberg identified and sorted through the last three issues and resulted in Hendry and von UngernSternberg (1981), or "HUS".

In DHSY, the equilibrium correction term was the four-quarter lag of the log of the ratio of expenditure to income, and it was highly seasonal. However, seasonal dummy variables were insignificant if one used Scheffé's method. About a week after DHSY's publication, Thomas von Ungern-Sternberg added seasonal dummies to that equation and, with conventional $t$-tests, found that they were highly significant. Care was clearly required with multiple-testing procedures. Those results on seasonality stimulated an industry on time-varying seasonal patterns, periodic seasonality, and periodic behavior, with many contributions by Denise Osborn $(1988,1991)$.

Also, DHSY found that liquid assets were not significant in their model: that result arose from a subtle form of mis-specification. HUS showed that, in an equilibrium correction formulation, imposing a long-run unit elasticity of expenditure with respect to income leaves no room for liquid assets. Methodologically speaking, DHSY were testing from simple to general, and not general enough. Once the long-run income elasticity was de-restricted, liquid assets were significant in DHSY's equation. HUS interpreted the role of liquid assets as a Phillips-type integral correction mechanism. Moreover, the combined effect of liquid assets and real income on expenditure added up to unity in the long run.

After DHSY and HUS, David produced a whole series of papers on consumers' expenditure. Davidson and Hendry (1981) found that lagged variables, as derived from HUS, were significant in explaining current changes in UK consumers' expenditure. HUS's model thus encompassed the Euler-equation approach in Hall (1978). Subsequent papers by David checked the constancy of the models and extended them. Hendry (1983) modeled annual interwar UK consumers' expenditure, obtaining results similar to the post-war quarterly relations in DHSY and HUS, despite large changes in the correlation structure of the data. Mizon and Hendry (1980) and Hendry (1992a) 
developed models of consumers' expenditure in Canada and France respectively; Hendry (1999) modeled interwar and post-war US food expenditure; and Hendry (1994) revisited HUS with yet additional data. Hendry, Muellbauer, and Murphy (1990) re-examined DHSY on an extended information set, finding that additional variables mattered - a result consistent with econometric theory in Sargan (1975) and White (1990). With an increasing sample size or information set, noncentral $t$-statistics become more significant, so models expand. These results also highlighted some of the challenges of empirical work. General-to-specific methodology provides guidelines for building encompassing models, but advances between studies are frequently simple-to-general, putting a premium on creative thinking.

\subsection{Money Demand}

David has analyzed money demand in many contexts, including narrow and broad money demand for both the United Kingdom and the United States. These analyses stimulated and were stimulated by interactions with various governmental bodies, and they resulted in significant press coverage as well.

David's first money-demand study-Hendry and Mizon (1978) - responded to work on quarterly narrow money (M1) and broad money (M3) demand by Graham Hacche (1974), then at the Bank of England. In back-to-back publications in the Economic Journal, Courakis (1978) criticized Hacche (1974) for differencing data in order to achieve stationarity, and Hendry and Mizon (1978) proposed testing the restrictions imposed by differencing with Denis Sargan's new common-factor test, later published as Sargan (1980). Additionally, Hendry and Mizon (1978) developed an equilibrium correction representation for quarterly M3, using the Bank's data. The common-factor restriction in Hacche (1974) was rejected, and the equilibrium correction term in Hendry and Mizon's (1978) model was significant.

Hendry and Mizon (1978) implicitly assumed that both the equilibrium correction term and the differences in their model would be stationary - despite no concept of cointegration - and that the significance of the equilibrium correction term was equivalent to rejecting the imposed common factor from differencing. Also, Hacche (1974) was specific to general in its approach, whereas Hendry and Mizon (1978) argued for general-to-specific modeling, which was also the natural way to test common-factor restrictions using Sargan's determinantal conditions. Sargan's COMFAC algorithm was already included in David's software program GIVE, with a Monte Carlo study of COMFAC appearing in Mizon and Hendry (1980).

A subsequent Bank of England study - of the monetary aggregate M1 by Richard Coghlan (1978) - considered general dynamic specifications, but they still lacked an equilibrium correction term. In Hendry (1979), David responded by showing how narrow money acts as a buffer for agents' expenditures, but with target ratios for money relative to expenditure, deviations from which prompt adjustment. That target ratio depended on the opportunity costs of holding money relative to alternative financial assets and to goods, as measured by interest rates and inflation respectively.

Hendry (1979) also highlighted problems confronting a simple-to-general approach, including the misinterpretation of earlier results in the modeling sequence, the impos- 
sibility of constructively interpreting test rejections, the many expansion paths faced, the unknown stopping point, the collapse of the strategy if later mis-specifications are detected, and the poor properties that result from stopping at the first non-rejection. These criticisms dated back to Anderson (1962) at least, but many modelers seemed unaware of them at the time. Parameter nonconstancy was another key difficulty with earlier UK money-demand equations. The model in Hendry (1979), however, was empirically constant over a sample with considerable turbulence after the introduction of Competition and Credit Control regulations in 1971.

Hendry (1979) served as the starting point for subsequent papers on UK M1, including Hendry (1985), Hendry and Ericsson (1991b), Ericsson, Hendry, and Tran (1994), and Doornik, Hendry, and Nielsen (1998). Despite a very general initial model, that research obtained a simple specification with only four key variables, which measured the opportunity costs of money against goods and other assets, adjustment costs, and the money market's disequilibrium.

Stimulated in part by several extended visits to the United States, David turned to modeling US M1, with results published in Baba, Hendry, and Starr (1992). As background, Goldfeld (1976) had recorded a supposed breakdown in US money demand in the early 1970s, so it was natural to implement models for US M1 similar to those that David had developed for UK M1. Andrew Rose, who was David's MPhil student at Nuffield College in the early 1980s, showed how econometric methodology contributed to Goldfeld's results. Goldfeld had modeled money demand as a partial adjustment model and had imposed short-run price homogeneity. Both of those features are dynamic restrictions and were rejected on the data. Rose (1985) started with a more general dynamic specification without those restrictions, modeled from general to specific, and found a money-demand model that was empirically constant over Goldfeld's sample and for several years thereafter.

However, even Rose's model showed parameter instability in the early 1980s. Many new financial instruments had been introduced, including money market mutual funds, CDs, and NOW and SuperNOW accounts. David hypothesized that these unaccounted-for financial innovations were the cause. Ross Starr also thought that long-term interest-rate volatility had changed the maturity structure of the bond market, especially when the Fed implemented its New Operating Procedures. Because high interest rates then became associated with high variances, a high long-term rate was no longer a signal to buy bonds: interest rates might go higher still and induce capital losses. This phenomenon suggested calculating a certainty-equivalent long-term interest rate - that is, the interest rate adjusted for risk.

Otherwise, David's approach to modeling US M1 was similar to his approach to modeling UK M1, with M1 being determined by the private sector, conditional on interest rates set by the central bank and the banking sector. The estimated long-run income elasticity for the United States was one half - consistent with the theory of transactions demand developed in Baumol (1952) and Tobin (1956), but contrasting with the estimated long-run elasticity of unity for the United Kingdom in Hendry (1979). That difference in elasticities could be explained by convenient and inexpensive overdraft facilities then available in the United Kingdom but not in the United States. 
David's model of US M1 generated controversy. Seminar presentations at the Fed produced a number of challenges from the audience, including the claim that the Fed had engineered a monetary expansion for Richard Nixon's re-election. Dummy variables for that period were insignificant when added to David's model: agents were willing to hold that money at the prevailing interest rates, and confirming valid conditioning. The model was also criticized for its lag structure, which captured average adjustment speeds in a large and complex economy. Some economists still regard the final formulation as too complicated, perhaps believing in a world that is inherently simple. Other economists were concerned about data mining, although data mining per se would be hard-pressed to produce the large $t$-values found, however many search paths were explored. The variables might proxy unmodeled effects, but their large $t$-statistics would be highly unlikely to arise by chance alone.

Modeling annual UK broad money demand generated even more controversy for David. In 1982, Milton Friedman and Anna Schwartz published their book Monetary Trends in the United States and the United Kingdom; and it had many potential policy implications. Early the following year, the Bank of England asked David to evaluate the econometrics in Friedman and Schwartz (1982) for the Bank's Panel of Academic Consultants. Neil Ericsson was David's research officer at the time, and their initial examination of Friedman and Schwartz (1982) revealed much. Methodologically, Friedman and Schwartz's approach was deliberately simple-to-general, commencing with bivariate regressions, generalizing to trivariate regressions, etc. Testing their equations found considerable mis-specification, including parameter nonconstancy, an anathema to money-demand equations. Also, Friedman and Schwartz had phaseaveraged their annual data in an attempt to remove business cycles, but phase averaging still left highly autocorrelated, nonstationary series. Because filtering (such as phase averaging) imposes dynamic restrictions, David and Neil analyzed both the phase-average data and the original annual data. In late October, David presented the research in Hendry and Ericsson (1983) to the Bank's Panel. Luminaries and rising stars in UK academia and government participated, including Chris Allsopp, Mike Artis, Andrew Bain, David Begg, Arthur Brown, Willem Buiter, Terry Burns, Ian Byatt, Alec Cairncross, Forrest Capie, Nicholas Dimsdale, Charles Goodhart, Jeroen Kremers, Rachel Lomax, R.C.O. Matthews, Ken Wallis, Geoffrey Wood, and David Worswick.

It is helpful to put that meeting at the Bank in historical context. Monetarism was at its peak. Margaret Thatcher - then Prime Minister - had instituted a regime of monetary control, as she believed that money caused inflation, precisely the view put forward by Friedman and Schwartz (1982). From this perspective, a credible monetary tightening would rapidly reduce inflation because expectations were rational. In fact, inflation fell slowly in Britain, whereas unemployment leapt to levels not seen since the 1930s. The UK House of Commons' Treasury and Civil Service Committee on Monetary Policy — which David had advised in Hendry (1981a, 1981b) - had found no evidence that monetary expansion was the cause of the high inflation in the 1970s. If anything, inflation caused money, whereas money was almost an epiphenomenon. The structure of the British banking system made the Bank of England a "lender of first resort", and so the Bank could only control the quantity of money by varying 
interest rates.

Shortly after the meeting of the Bank's Panel of Academic Consultants, Hendry and Ericsson (1983) received considerable press coverage, starting with the British newspaper The Guardian and spilling over into other newspapers around the world. Chris Huhne - The Guardian's economics editor at the time - had seen Hendry and Ericsson (1983); and he deemed the evidence therein central to the policy debate. On December 15, 1983, The Guardian published two articles about Friedman and Schwartz (1982). On page 19 of the newspaper, Huhne had authored an article that summarized - in layman's terms - the critique by Hendry and Ericsson (1983) of Friedman and Schwartz (1982). David and Chris had discussed Hendry and Ericsson (1983) at length beforehand; and Chris's article - "Why Milton's monetarism is bunk" - provided an accurate statement of Hendry and Ericsson (1983) and its implications. In addition, The Guardian decided to run a front-page editorial on Friedman and Schwartz (1982) with the headline "Monetarism's guru 'distorts his evidence'". That headline summarized Huhne's view that it was unacceptable for Friedman and Schwartz to use their data-based dummy variable for 1921-1955 and still claim parameter constancy of their money-demand equation. Rather, the statistical, numerical, and economic significance of that dummy variable actually implied nonconstancy, as Goodhart (1982) also discussed. Moreover, Hendry and Ericsson (1983) had shown that Friedman and Schwartz's money-demand equation was empirically nonconstant, even with their dummy variable. Nonconstancy undermined Friedman and Schwartz's policy conclusions. Chris later did a TV program about the debate, spending a day at David's house filming.

Hendry and Ericsson (1983) started a modeling sequence that included Longbottom and Holly (1985), Escribano (1985), and (after a prolonged editorial process) Hendry and Ericsson (1991a). Attfield, Demery, and Duck (1995) subsequently claimed that the money-demand equation in Hendry and Ericsson (1991a) had broken down on data extended to the early 1990s, whereas the Friedman and Schwartz's specification was constant. To compile a coherent statistical series over the extended sample period, Attfield, Demery, and Duck (1995) had spliced several different money measures together, but they had not adjusted the corresponding measures of the opportunity cost. With that combination, the model in Hendry and Ericsson (1991a) did indeed fail. Ericsson, Hendry, and Prestwich (1998) showed that that model remained constant over the whole sample with an appropriate measure of opportunity cost, whereas the model of Friedman and Schwartz failed. Escribano (2004) updated the equation from Hendry and Ericsson (1991a) through 2000 and confirmed its continued constancy.

Ericsson, Hendry, and Hood (2016) subsequently examined the US money-demand equations in Friedman and Schwartz (1982), finding substantial empirical shortcomings, even by Friedman's own criteria, such as subsample properties. Ericsson, Hendry, and Hood (2016) highlighted difficulties with Friedman and Schwartz's simpleto-general methodology and showed that Friedman and Schwartz's final US moneydemand equation had nonconstant parameters and that its residuals were heteroscedastic, even though that equation's estimation included an adjustment for the heteroscedasticity induced by the phase averaging of the annual data. Furthermore, Friedman and Schwartz's data adjustment for the United States' increasing relative fi- 
nancial sophistication did not adequately capture the financial changes that occurred in the sample.

\subsection{Television and Ofcom}

David also worked with the UK government's Office of Communications (Ofcom) on forecasts of net advertising revenue for the TV broadcasting network ITV. These forecasts had significant policy consequences and are of interest in their own right.

Ofcom is the British government agency responsible for regulating the UK telecommunication and postal industries, including the licensing of UK TV broadcasting. In 2004, Ofcom needed to price the renewal of the advertising license for ITV, the oldest and biggest commercial TV network in the United Kingdom. The license fee had been specified to be calculated from forecasts of discounted net advertising revenue (NAR) over the subsequent decade.

Hendry (1992b) had developed a VEqCM for key variables in forecasting NAR hours broadcast, audience reach, and the price of advertising time. David subsequently improved that VEqCM using PcGets. Ofcom then augmented that new $\mathrm{VEqCM}$ by forecasts from a macro-model for variables such as GDP, company profits, interest rates, and inflation.

In forecasting NAR, Ofcom initially preferred to forecast from that augmented $\mathrm{VEqCM}$, rather than from the corresponding DVEqCM. Ofcom was concerned with how the differencing in the DVEqCM would eliminate long-run relationships from the $\mathrm{VEqCM}$. However, representatives from the advertising industry described recent breaks in TV advertising that arose from innovations such as video recorders, Internet advertising, and alternative TV channels. Those breaks would be difficult to model with available data, yet they could cause systematic forecast failure by the VEqCM. David persuaded Ofcom that differencing the VEqCM would robustify their forecasts, removing effects of those location shifts but retaining long-run information; see Section 4.3.

Ofcom published forecasts for NAR over 2004-2014 in Raven, Hoehn, Lancefield, and Robinson (2004, Figure 6.5). Forecasts were calculated from three models: a "long-run trend" model, the VEqCM, and the corresponding DVEqCM. Those models' forecasts were respectively increasing, relatively flat, and slightly declining over time. Robustification was consequential because of recent unmodeled shifts. Robustification by differencing the $\mathrm{VEqCM}$ removed location shifts in excluded variables such as the introduction of personal video recorders, which had reduced TV advertising revenue.

These forecasts were key to setting policy: Ofcom set a lower license fee because the DVEqCM forecasts showed NAR declining, rather than increasing. However, while the DVEqCM did perform the best of the three models ex post, even its forecasts proved too optimistic. Many of the variables included in the DVEqCM themselves experienced unanticipated location shifts during the forecast period. For instance, in the wake of the financial crisis, actual GDP and profits were much lower than forecast, poignantly illustrating that unanticipated location shifts can induce systematic forecast errors. 


\subsection{Climate Change}

David has had a longstanding interest in the natural sciences, including in paleontology and geology. From his readings on these topics and from discussions with experts, David became concerned about anthropogenic influences in climate change and the economic consequences thereof. At the time, much climate science was nonstochastic and scenario-driven, so David saw a role for econometrics in advancing understanding and driving policy.

Hendry (2011) - David's initial foray into climate econometrics - examines geologic evidence on climate change and its role in great extinctions. Relatedly, Castle and Hendry (2020b) derive the causal role of atmospheric $\mathrm{CO}_{2}$ levels in past Ice Ages. Hendry and Pretis (2013) turn to relatively recent evidence from the Mauna Loa observatory, using IIS and automatic model selection across a wide range of climatic and economic variables to determine the extent to which anthropogenic sources increase atmospheric $\mathrm{CO}_{2}$. Their model controls for a number of natural carbon sources and sinks - such as vegetation, temperature, weather, and dynamic transport - and determines the additional anthropogenic contributions from industrial production, business cycles, and shocks. The anthropogenic sources are significant contributors to changes in atmospheric $\mathrm{CO}_{2}$. Pretis and Hendry (2013) illustrate how advances in econometric methodology can improve existing studies of global warming. Pretis, Schneider, Smerdon, and Hendry (2016) develop saturation procedures using "designer breaks" to detect and identify volcanic eruptions, some of which created strong albeit temporary climatic changes.

In 2015, David and Felix Pretis received a $£ 660,000$ grant from the Robertson Foundation to support their research program Climate Econometrics, ably managed by Angela Wenham. The program serves as a key catalyst for wide-ranging econometric advances in climate change, with several recent developments. Pretis (2020) shows the equivalence of energy balance models and cointegrated vector autoregressions. David's former DPhil student Andrew Martinez (2020a) uses a multidisciplinary approach with automated model selection to show that larger errors in a hurricane's predicted landfall increase the hurricane's damages; see also Martinez (2020b). Hendry (2020) and Castle and Hendry (2020a) model $\mathrm{CO}_{2}$ emissions in the United Kingdom over the last century and a half using saturation techniques and automatic model selection. Over the last several decades, emissions have dropped dramatically to pre-1900 levels, even while real income increased manyfold, with legislation and technological improvements being key factors in the reduction. To paraphrase the title of David's 2020 paper ("First In, First Out"), Britain was the first country into the industrial revolution - then producing a large share of global anthropogenic $\mathrm{CO}_{2}$ emissions - and Britain is now becoming one of the first countries out. On April 22, 2017, Britain had its first full day in over a century with no electricity being produced by coal-fired plants. In April 2020, electricity production in Britain went for 18 consecutive days coal-free. While climate change remains a major global chal-

lenge, progress can be made. Modern dynamic econometric analysis can shed light on climate change and help guide policy. 


\section{Oxford Connections}

David spent the first decade and a half of his professional career in London at the LSE-first as a student in the MSc and PhD programs, then as a Lecturer and Professor. In January 1982, he moved to Nuffield College, Oxford. He has been at Nuffield ever since. Nuffield College itself is a college of only graduate students in the social sciences and, as such, attracted remarkable students and colleagues, many becoming co-authors on David's research projects.

The move to Oxford appealed to David for many reasons. Oxford provided a good research environment with many excellent economists, it had bright students, and it was a lovely place to live. David and Evelyn's daughter Vivien was about to start school, and Oxford schools were preferable to those in central London. Amartya Sen, Terence Gorman, and John Muellbauer had all recently moved to Oxford; Jim Mirrlees was already there. Steve Nickell and David Cox were soon to arrive.

In Oxford, David was initially also the acting director of the university's Institute of Economics and Statistics. The Institute transmogrified into the university's Department of Economics in 1999, which David later chaired. In 2007, the Department was the focus for David's Festschrift, published as Castle and Shephard (2009).

When David arrived in Oxford, the university had no economics department, and no undergraduate economics degree either. Economics was college-based rather than university-based, it lacked a building, and it had little secretarial support. PPEshort for "Philosophy, Politics, and Economics" — was the major vehicle through which Oxford undergraduates learnt economics. With the creation of a department of economics, the university moved to a more integrated teaching program at both the graduate and the undergraduate levels. Even so, the university still has no undergraduate program strictly in economics: only PPE and E\&M (Economics and Management).

The Institute of Economics and Statistics also housed the Oxford Bulletin of Economics and Statistics, which David began editing. He saw that a shift in focus would benefit the journal, and this was helped by commissioning two timely special issues on cointegration that attracted the profession's attention-Hendry (1986a) and Banerjee and Hendry (1992a); see Section 2.2. Some people then nicknamed the journal the Oxford Bulletin of Cointegration, reflecting the pivotal and highly cited articles on cointegration that it published.

Research funding proved critical to David's activities in Oxford. Although many of his research grant applications for forecasting were rejected, he was awarded two personal research fellowships: one from the Leverhulme Trust for five years, and one from the Economic and Social Research Council for three years. These fellowships bought out some of his teaching responsibilities, enabling him to develop the general theory of forecasting. Additionally, James Martin and George Soros generously funded his program Economic Modelling (EMoD) - James Martin through the Oxford Martin School, and George Soros through the Open Society Foundations and the Institute for New Economic Thinking (INET). The initial five-year grant for EMoD supported Oxford economics faculty and post-doctoral research fellows in analyzing difficulties that empirical modeling, economic analysis, policy, and forecasting confront with rapid unanticipated changes. INET extended David's EMoD grant for three more 
years jointly with John Muellbauer; and the Robertson Foundation awarded a grant for David and Felix Pretis's program Climate Econometrics.

Research topics at EMoD and Climate Econometrics are manifold. They include analyzing the mathematical and statistical bases for expectations formation and intertemporal optimization when economic agents face unanticipated breaks, and developing methods of empirical model discovery that can handle multiple intermittent shifts. EMoD also investigated inequality in wealth and income, established a webaccessible database of civilization's progress (www.OurWorldInData.org), modeled immigration into Norway, and formulated alternative macro-models with financial channels. At Climate Econometrics, saturation methods for detecting breaks are isolating the effects of volcanic eruptions on temperature, detecting policy-driven shifts in $\mathrm{CO}_{2}$ emissions, and helping to model increases in sea level. The overriding theme is to develop approaches appropriate to a world undergoing rapid unanticipated changes, and to improve forecasting methods in such a setting.

\section{Conclusion}

David Hendry has made pathbreaking contributions to econometrics: in modeling, in forecasting, in software, and in policy. Hendry (1995), Banerjee, Dolado, Galbraith, and Hendry (1993), and Hendry and Doornik (2014) - three pioneering books on econometric methodology, cointegration, and model design - set the foundations for systematic empirical economic modeling with machine learning. David has applied that approach to a wide range of substantive empirical studies, including on consumers' expenditure, mortgage and housing markets, money demand, and climate change.

In economic forecasting, David and Mike Clements developed a taxonomy of forecast errors that has yielded valuable insights into the nature of forecasting. Davidoften with Mike and (more recently) Jennie Castle - has provided new perspectives on many existing forecast techniques, including mean square forecast errors, add factors, leading indicators, pooling of forecasts, and multi-step estimation. David has also developed new forecast tools, such as forecast encompassing; and he has improved existing ones, such as nowcasting and the robustification of forecasts to breaks.

David's studies in modeling and forecasting have had direct implications for economic policy. Practical implementation and assessment in modeling, forecasting, and policy require computer software; and David and Jurgen Doornik's suite of software packages continues to embody best-practice econometrics. Overlaps are common between different strands in David's research, with the analysis of real-world problems motivating and benefiting from that research. 


\section{Main and Cited Works by David F. Hendry}

Anderson, G. J., and D. F. Hendry (1984) "An Econometric Model of United Kingdom Building Societies", Oxford Bulletin of Economics and Statistics, 46, 3, 185-210.

Baba, Y., D. F. Hendry, and R. M. Starr (1992) "The Demand for M1 in the U.S.A., 1960-1988", Review of Economic Studies, 59, 1, 25-61.

Banerjee, A., J. J. Dolado, J. W. Galbraith, and D. F. Hendry (1993) Co-integration, Error Correction, and the Econometric Analysis of Non-stationary Data, Oxford University Press, Oxford.

Banerjee, A., J. J. Dolado, D. F. Hendry, and G. W. Smith (1986) "Exploring Equilibrium Relationships in Econometrics Through Static Models: Some Monte Carlo Evidence", Oxford Bulletin of Economics and Statistics, 48, 3, 253-277.

Banerjee, A., and D. F. Hendry (eds.) (1992a) Testing Integration and Cointegration, Special Issue, Oxford Bulletin of Economics and Statistics, 54, 3, August.

Banerjee, A., and D. F. Hendry (1992b) "Testing Integration and Cointegration: An Overview", Oxford Bulletin of Economics and Statistics, 54, 3, 225-255.

Banerjee, A., and D. F. Hendry (eds.) (1996) The Econometrics of Economic Policy, Special Issue, Oxford Bulletin of Economics and Statistics, 58, 4, November.

Banerjee, A., and D. F. Hendry (eds.) (1997) The Econometrics of Economic Policy, Blackwell Publishers, Oxford.

Barnett, W. A., D. F. Hendry, S. Hylleberg, T. Teräsvirta, D. Tjøstheim, and A. Würtz (eds.) (2000) Nonlinear Econometric Modeling in Time Series: Proceedings of the Eleventh International Symposium in Economic Theory, Cambridge University Press, Cambridge.

Campos, J., N. R. Ericsson, and D. F. Hendry (1996) "Cointegration Tests in the Presence of Structural Breaks", Journal of Econometrics, 70, 1, 187-220.

Campos, J., N. R. Ericsson, and D. F. Hendry (eds.) (2005) General-to-Specific Modelling, Edward Elgar, Cheltenham (Volumes I and II).

Castle, J. L., M. P. Clements, and D. F. Hendry (2013) "Forecasting by Factors, by Variables, by Both or Neither?", Journal of Econometrics, 177, 2, 305-319.

Castle, J. L., M. P. Clements, and D. F. Hendry (2015) "Robust Approaches to Forecasting", International Journal of Forecasting, 31, 1, 99-112.

Castle, J. L., M. P. Clements, and D. F. Hendry (2019) Forecasting: An Essential Introduction, Yale University Press, New Haven and London.

Castle, J. L., J. A. Doornik, and D. F. Hendry (2012) "Model Selection When There Are Multiple Breaks", Journal of Econometrics, 169, 2, 239-246.

Castle, J. L., J. A. Doornik, and D. F. Hendry (2020a) "COVID-19 Short-term Forecasts", www.doornik.com/COVID-19/, University of Oxford, Oxford.

Castle, J. L., J. A. Doornik, and D. F. Hendry (2020b) "Medium-term Forecasting of the Coronavirus Pandemic", draft, Nuffield College, University of Oxford, Oxford, May.

Castle, J. L., and D. F. Hendry (eds.) (2017) Sir Clive W. J. Granger Memorial Special Issue on Econometrics, European Journal of Pure and Applied Mathematics, 10, 1.

Castle, J. L., and D. F. Hendry (2019) Modelling Our Changing World, Palgrave Macmillan, Cham, Switzerland.

Castle, J. L., and D. F. Hendry (2020a) "Climate Econometrics: An Overview", Foundations and Trends in Econometrics, 10, 3-4, 145-322.

Castle, J. L., and D. F. Hendry (2020b) "Identifying the Causal Role of $\mathrm{CO}_{2}$ during the Ice Ages", Discussion Paper No. 898, Department of Economics, University of Oxford, Oxford, January. 
Castle, J. L., D. F. Hendry, and O. Kitov (2017) "Forecasting and Nowcasting Macroeconomic Variables: A Methodological Overview", Chapter 3 in Gian Luigi Mazzi and Dominique Ladiray (ed.) Handbook on Rapid Estimates: 2017 Edition, European Union, Luxembourg, 53-120.

Chong, Y. Y., and D. F. Hendry (1986) "Econometric Evaluation of Linear Macro-economic Models", Review of Economic Studies, 53, 4, 671-690.

Clements, M. P., and D. F. Hendry (1993) "On the Limitations of Comparing Mean Square Forecast Errors", Journal of Forecasting, 12, 8, 617-637 (with discussion).

Clements, M. P., and D. F. Hendry (1994) "Towards a Theory of Economic Forecasting", Chapter 2 in C. P. Hargreaves (ed.) Nonstationary Time Series Analysis and Cointegration, Oxford University Press, Oxford, 9-52.

Clements, M. P., and D. F. Hendry (1995) "Forecasting in Cointegrated Systems", Journal of Applied Econometrics, 10, 2, 127-146.

Clements, M. P., and D. F. Hendry (1996a) "Intercept Corrections and Structural Change", Journal of Applied Econometrics, 11, 5, 475-494.

Clements, M. P., and D. F. Hendry (1996b) "Multi-step Estimation for Forecasting", Oxford Bulletin of Economics and Statistics, 58, 4, 657-684.

Clements, M. P., and D. F. Hendry (1998a) "Forecasting Economic Processes", International Journal of Forecasting, 14, 1, 111-131 (with discussion).

Clements, M. P., and D. F. Hendry (1998b) Forecasting Economic Time Series, Cambridge University Press, Cambridge.

Clements, M. P., and D. F. Hendry (1999a) Forecasting Non-stationary Economic Time Series, MIT Press, Cambridge.

Clements, M. P., and D. F. Hendry (1999b) "On Winning Forecasting Competitions in Economics", Spanish Economic Review, 1, 2, 123-160.

Clements, M. P., and D. F. Hendry (2001) "Explaining the Results of the M3 Forecasting Competition", International Journal of Forecasting, 17, 4, 550-554.

Clements, M. P., and D. F. Hendry (eds.) (2002a) A Companion to Economic Forecasting, Blackwell Publishers, Oxford.

Clements, M. P., and D. F. Hendry (2002b) "An Overview of Economic Forecasting", Chapter 1 in M. P. Clements and D. F. Hendry (eds.) A Companion to Economic Forecasting, Blackwell Publishers, Oxford, 1-18.

Clements, M. P., and D. F. Hendry (2003) "Report of a Scoping Study of Forecasting in the National Accounts at the Office for National Statistics", Annex A in Forecasting in the National Accounts at the Office for National Statistics, Statistics Commission Report No. 12, Statistics Commission, London, December.

Clements, M. P., and D. F. Hendry (2005a) "Guest Editors' Introduction: Information in Economic Forecasting", Oxford Bulletin of Economics and Statistics, 67, Supplement, 713-753.

Clements, M. P., and D. F. Hendry (eds.) (2005b) Information in Economic Forecasting, Special Issue, Oxford Bulletin of Economics and Statistics, 67, Supplement.

Clements, M. P., and D. F. Hendry (2006) "Forecasting with Breaks", Chapter 12 in G. Elliott, C. W. J. Granger, and A. Timmermann (eds.) Handbook of Economic Forecasting, Volume 1, Elsevier, Amsterdam, 605-657.

Clements, M. P., and D. F. Hendry (eds.) (2011) Oxford Handbook of Economic Forecasting, Oxford University Press, Oxford.

Davidson, J. E. H., and D. F. Hendry (1981) "Interpreting Econometric Evidence: The Behaviour of Consumers' Expenditure in the UK", European Economic Review, 16, 1, 177-192 (with discussion). 
Davidson, J. E. H., D. F. Hendry, F. Srba, and S. Yeo (1978) "Econometric Modelling of the Aggregate Time-series Relationship Between Consumers' Expenditure and Income in the United Kingdom", Economic Journal, 88, 352, 661-692.

Doornik, J. A., J. L. Castle, and D. F. Hendry (2020a) "Card Forecasts for M4", International Journal of Forecasting, 36, 1, 129-134.

Doornik, J. A., J. L. Castle, and D. F. Hendry (2020b) "Statistical Short-term Forecasting of the COVID-19 Pandemic", Journal of Clinical Immunology and Immunotherapy, 6, $5,046,1-5$.

Doornik, J. A., J. L. Castle, and D. F. Hendry (2021) "Short-term Forecasting of the Coronavirus Pandemic", International Journal of Forecasting, in press.

Doornik, J. A., and D. F. Hendry (1992) PcGive Version 7: An Interactive Econometric Modelling System, Institute of Economics and Statistics, University of Oxford, Oxford.

Doornik, J. A., and D. F. Hendry (1994) PcFiml 8.0: Interactive Econometric Modelling of Dynamic Systems, International Thomson Publishing, London.

Doornik, J. A., and D. F. Hendry (2001) PcGive Version 10 for Windows, Timberlake Consultants Press, London (5 volumes).

Doornik, J. A., and D. F. Hendry (2007) PcGive 12: Empirical Econometric Modelling, Volume I, Timberlake Consultants Press, London.

Doornik, J. A., and D. F. Hendry (2018) PcGive 15, Timberlake Consultants Ltd, Richmond, UK (3 volumes).

Doornik, J. A., D. F. Hendry, and B. Nielsen (1998) "Inference in Cointegrating Models: UK M1 Revisited", Journal of Economic Surveys, 12, 5, 533-572.

Emerson, R. A., and D. F. Hendry (1996) "An Evaluation of Forecasting Using Leading Indicators", Journal of Forecasting, 15, 4, 271-291.

Engle, R. F., D. F. Hendry, and J.-F. Richard (1983) "Exogeneity", Econometrica, 51, 2, $277-304$.

Ericsson, N. R., and D. F. Hendry (1985) "Conditional Econometric Modeling: An Application to New House Prices in the United Kingdom", Chapter 11 in A. C. Atkinson and S. E. Fienberg (eds.) A Celebration of Statistics: The ISI Centenary Volume, SpringerVerlag, New York, 251-285.

Ericsson, N. R., D. F. Hendry, and S. B. Hood (2016) "Milton Friedman as an Empirical Modeler", Chapter 6 in R. A. Cord and J. D. Hammond (eds.) Milton Friedman: Contributions to Economics and Public Policy, Oxford University Press, Oxford, 91-142.

Ericsson, N. R., D. F. Hendry, and K. M. Prestwich (1998) "The Demand for Broad Money in the United Kingdom, 1878-1993", Scandinavian Journal of Economics, 100, 1, 289324 (with discussion).

Ericsson, N. R., D. F. Hendry, and H.-A. Tran (1994) "Cointegration, Seasonality, Encompassing, and the Demand for Money in the United Kingdom", Chapter 7 in C. P. Hargreaves (ed.) Nonstationary Time Series Analysis and Cointegration, Oxford University Press, Oxford, 179-224.

Haldrup, N., D. F. Hendry, and H. K. van Dijk (eds.) (2003) Model Selection and Evaluation, Special Issue, Oxford Bulletin of Economics and Statistics, 65, supplement.

Hendry, D. F. (1973) "On Asymptotic Theory and Finite Sample Experiments", Economica, $40,158,210-217$.

Hendry, D. F. (1974) "Stochastic Specification in an Aggregate Demand Model of the United Kingdom", Econometrica, 42, 3, 559-578.

Hendry, D. F. (1975) "The Consequences of Mis-specification of Dynamic Structure, Autocorrelation, and Simultaneity in a Simple Model with an Application to the Demand for Imports", Chapter 11 in G. A. Renton (ed.) Modelling the Economy, Heinemann Educational Books, London, 286-320 (with discussion). 
Hendry, D. F. (1976) "The Structure of Simultaneous Equations Estimators", Journal of Econometrics, 4, 1, 51-88.

Hendry, D. F. (1977) "Comments on Granger-Newbold's 'Time Series Approach to Econometric Model Building' and Sargent-Sims' 'Business Cycle Modeling Without Pretending to Have Too Much A Priori Economic Theory'", in C. A. Sims (ed.) New Methods in Business Cycle Research: Proceedings from a Conference, Federal Reserve Bank of Minneapolis, Minneapolis, 183-202.

Hendry, D. F. (1979) "Predictive Failure and Econometric Modelling in Macroeconomics: The Transactions Demand for Money", Chapter 9 in P. Ormerod (ed.) Economic Modelling: Current Issues and Problems in Macroeconomic Modelling in the UK and the US, Heinemann Education Books, London, 217-242.

Hendry, D. F. (1980) "Econometrics-Alchemy or Science?", Economica, 47, 188, 387-406.

Hendry, D. F. (1981a) "Comment on HM Treasury's Memorandum, 'Background to the Government's Economic Policy", in House of Commons (ed.) Third Report from the Treasury and Civil Service Committee, Session 1980-81, Monetary Policy, Volume 3, Her Majesty's Stationery Office, London, 94-96 (Appendix 4).

Hendry, D. F. (1981b) "Econometric Evidence in the Appraisal of Monetary Policy", in House of Commons (ed.) Third Report from the Treasury and Civil Service Committee, Session 1980-81, Monetary Policy, Volume 3, Her Majesty's Stationery Office, London, 1-21 (Appendix 1).

Hendry, D. F. (1983) "Econometric Modelling: The 'Consumption Function' in Retrospect", Scottish Journal of Political Economy, 30, 3, 193-220.

Hendry, D. F. (1984a) "Econometric Modelling of House Prices in the United Kingdom", Chapter 8 in D. F. Hendry and K. F. Wallis (eds.) Econometrics and Quantitative Economics, Basil Blackwell, Oxford, 211-252.

Hendry, D. F. (1984b) "Monte Carlo Experimentation in Econometrics", Chapter 16 in Z. Griliches and M. D. Intriligator (eds.) Handbook of Econometrics, Volume 2, NorthHolland, Amsterdam, 937-976.

Hendry, D. F. (1985) "Monetary Economic Myth and Econometric Reality", Oxford Review of Economic Policy, 1, 1, 72-84.

Hendry, D. F. (ed.) (1986a) Econometric Modelling with Cointegrated Variables, Special Issue, Oxford Bulletin of Economics and Statistics, 48, 3, August.

Hendry, D. F. (1986b) "Econometric Modelling with Cointegrated Variables: An Overview", Oxford Bulletin of Economics and Statistics, 48, 3, 201-212.

Hendry, D. F. (1986c) "Empirical Modeling in Dynamic Econometrics", Applied Mathematics and Computation, 20, 3/4, 201-236.

Hendry, D. F. (1986d) "The Role of Prediction in Evaluating Econometric Models", Proceedings of the Royal Society of London, Series A, 407, 1832, 25-34 (with discussion).

Hendry, D. F. (1987a) "Econometric Methodology: A Personal Perspective", Chapter 10 in T. F. Bewley (ed.) Advances in Econometrics: Fifth World Congress, Volume 2, Cambridge University Press, Cambridge, 29-48.

Hendry, D. F. (1987b) PC-GIVE: An Interactive Menu-driven Econometric Modelling Program for IBM-compatible PC's, Version 4.2, Institute of Economics and Statistics and Nuffield College, University of Oxford, Oxford, January.

Hendry, D. F. (1991) "Economic Forecasting: A Report to the Treasury and Civil Service Committee", submitted to the House of Commons, Memoranda on Official Economic Forecasting, Treasury and Civil Service Committee, Session 1990-91, Her Majesty's Stationery Office, London, July 12.

Hendry, D. F. (1992a) "Assessing Empirical Evidence in Macroeconometrics with an Application to Consumers' Expenditure in France", Chapter 13 in A. Vercelli and N. Dimitri 
(eds.) Macroeconomics: A Survey of Research Strategies, Oxford University Press, Oxford, 363-392.

Hendry, D. F. (1992b) "An Econometric Analysis of TV Advertising Expenditure in the United Kingdom", Journal of Policy Modeling, 14, 3, 281-311.

Hendry, D. F. (1993) Econometrics: Alchemy or Science? Essays in Econometric Methodology, Blackwell Publishers, Oxford.

Hendry, D. F. (1994) "HUS Revisited", Oxford Review of Economic Policy, 10, 2, 86-106.

Hendry, D. F. (1995) Dynamic Econometrics, Oxford University Press, Oxford.

Hendry, D. F. (1997) "On Congruent Econometric Relations: A Comment", CarnegieRochester Conference Series on Public Policy, 47, December, 163-190.

Hendry, D. F. (1999) "An Econometric Analysis of US Food Expenditure, 1931-1989", Chapter 17 in J. R. Magnus and M. S. Morgan (eds.) Methodology and Tacit Knowledge: Two Experiments in Econometrics, John Wiley and Sons, Chichester, 341-361.

Hendry, D. F. (2000) Econometrics: Alchemy or Science? Essays in Econometric Methodology, Oxford University Press, Oxford, New Edition.

Hendry, D. F. (2004) "The Nobel Memorial Prize for Clive W. J. Granger", Scandinavian Journal of Economics, 106, 2, 187-213.

Hendry, D. F. (2006) "Robustifying Forecasts from Equilibrium-correction Systems", Journal of Econometrics, 135, 1-2, 399-426.

Hendry, D. F. (2011) "Climate Change: Lessons for Our Future from the Distant Past", Chapter 2 in S. Dietz, J. Michie, and C. Oughton (eds.) The Political Economy of the Environment: An Interdisciplinary Approach, Routledge, Abington, 19-43.

Hendry, D. F. (2015) Introductory Macro-econometrics: A New Approach, Timberlake Consultants Ltd., London.

Hendry, D. F. (2020) "First In, First Out: Econometric Modelling of UK Annual $\mathrm{CO}_{2}$ Emissions, 1860-2017", Economics Discussion Paper No. 2020-W02, Nuffield College, University of Oxford, Oxford, February.

Hendry, D. F., and G. J. Anderson (1977) "Testing Dynamic Specification in Small Simultaneous Systems: An Application to a Model of Building Society Behavior in the United Kingdom", Chapter 8c in M. D. Intriligator (ed.) Frontiers of Quantitative Economics, Volume 3A, North-Holland, Amsterdam, 361-383.

Hendry, D. F., and M. P. Clements (1994a) "Can Econometrics Improve Economic Forecasting?", Swiss Journal of Economics and Statistics, 130, 3, 267-298.

Hendry, D. F., and M. P. Clements (1994b) "On a Theory of Intercept Corrections in Macroeconometric Forecasting", Chapter 8 in S. Holly (ed.) Money, Inflation and Employment: Essays in Honour of James Ball, Edward Elgar, Aldershot, 160-182.

Hendry, D. F., and M. P. Clements (2004) "Pooling of Forecasts", Econometrics Journal, $7,1,1-31$.

Hendry, D. F., and J. A. Doornik (1997) "The Implications for Econometric Modelling of Forecast Failure", Scottish Journal of Political Economy, 44, 4, 437-461.

Hendry, D. F., and J. A. Doornik (1999) "The Impact of Computational Tools on Timeseries Econometrics", in T. Coppock (ed.) Information Technology and Scholarship: Applications in the Humanities and Social Sciences, Oxford University Press, Oxford, 257-269.

Hendry, D. F., and J. A. Doornik (2014) Empirical Model Discovery and Theory Evaluation: Automatic Selection Methods in Econometrics, MIT Press, Cambridge, Massachusetts.

Hendry, D. F., J. A. Doornik, and I. Hiroya (2006) Empirical Econometric Modelling Using PcGive 10, Nippon-Hyoron-Ska, Tokyo (in Japanese). 
Hendry, D. F., and N. R. Ericsson (1983) "Assertion Without Empirical Basis: An Econometric Appraisal of 'Monetary Trends in ... the United Kingdom' by Milton Friedman and Anna Schwartz", in Monetary Trends in the United Kingdom, Bank of England Panel of Academic Consultants, Panel Paper No. 22, Bank of England, London, October, 45-101.

Hendry, D. F., and N. R. Ericsson (1991a) "An Econometric Analysis of U.K. Money Demand in Monetary Trends in the United States and the United Kingdom by Milton Friedman and Anna J. Schwartz", American Economic Review, 81, 1, 8-38.

Hendry, D. F., and N. R. Ericsson (1991b) "Modeling the Demand for Narrow Money in the United Kingdom and the United States", European Economic Review, 35, 4, 833-881 (with discussion).

Hendry, D. F., and N. R. Ericsson (eds.) (2001) Understanding Economic Forecasts, MIT Press, Cambridge.

Hendry, D. F., and K. Hubrich (2011) "Combining Disaggregate Forecasts or Combining Disaggregate Information to Forecast an Aggregate", Journal of Business and Economic Statistics, 29, 2, 216-227.

Hendry, D. F., and S. Johansen (2015) "Model Discovery and Trygve Haavelmo's Legacy", Econometric Theory, 31, 1, 93-114.

Hendry, D. F., S. Johansen, and C. Santos (2008) "Automatic Selection of Indicators in a Fully Saturated Regression", Computational Statistics, 23, 2, 317-335, 337-339.

Hendry, D. F., and H.-M. Krolzig (1999) "Improving on 'Data Mining Reconsidered' by K. D. Hoover and S. J. Perez", Econometrics Journal, 2, 2, 202-219.

Hendry, D. F., and H.-M. Krolzig (2001) Automatic Econometric Model Selection Using PcGets 1.0, Timberlake Consultants Press, London.

Hendry, D. F., and H.-M. Krolzig (2005) "The Properties of Automatic Gets Modelling", Economic Journal, 115, 502, C32-C61.

Hendry, D. F., M. Marcellino, and G. E. Mizon (2008) Encompassing, Special Issue, Oxford Bulletin of Economics and Statistics, 70, Supplement, December.

Hendry, D. F., and A. B. Martinez (2017) "Evaluating Multi-step System Forecasts with Relatively Few Forecast-error Observations", International Journal of Forecasting, 33, $2,359-372$.

Hendry, D. F., and G. E. Mizon (1978) "Serial Correlation as a Convenient Simplification, Not a Nuisance: A Comment on a Study of the Demand for Money by the Bank of England", Economic Journal, 88, 351, 549-563.

Hendry, D. F., and G. E. Mizon (1993) "Evaluating Dynamic Econometric Models by Encompassing the VAR", Chapter 18 in P. C. B. Phillips (ed.) Models, Methods, and Applications of Econometrics: Essays in Honor of A. R. Bergstrom, Basil Blackwell, Cambridge, 272-300.

Hendry, D. F., and G. E. Mizon (2000a) "On Selecting Policy Analysis Models by Forecast Accuracy", Chapter 5 in A. B. Atkinson, H. Glennerster, and N. H. Stern (eds.) Putting Economics to Work: Volume in Honour of Michio Morishima, STICERD, London School of Economics, London, 71-119.

Hendry, D. F., and G. E. Mizon (2000b) "Reformulating Empirical Macroeconometric Modelling", Oxford Review of Economic Policy, 16, 4, 138-159.

Hendry, D. F., and G. E. Mizon (2014) "Unpredictability in Economic Analysis, Econometric Modeling and Forecasting", Journal of Econometrics, 182, 1, 186-195.

Hendry, D. F., and M. S. Morgan (eds.) (1995) The Foundations of Econometric Analysis, Cambridge University Press, Cambridge. 
Hendry, D. F., J. N. J. Muellbauer, and A. Murphy (1990) "The Econometrics of DHSY", Chapter 13 in J. D. Hey and D. Winch (eds.) A Century of Economics: 100 Years of the Royal Economic Society and the Economic Journal, Basil Blackwell, Oxford, 298-334.

Hendry, D. F., and A. J. Neale (1988) "Interpreting Long-run Equilibrium Solutions in Conventional Macro Models: A Comment", Economic Journal, 98, 392, 808-817.

Hendry, D. F., and A. J. Neale (1991) "A Monte Carlo Study of the Effects of Structural Breaks on Tests for Unit Roots", Chapter 8 in P. Hackl and A. H. Westlund (eds.) Economic Structural Change: Analysis and Forecasting, Springer-Verlag, Berlin, 95119.

Hendry, D. F., A. J. Neale, and N. R. Ericsson (1990) PC-NAIVE: An Interactive Program for Monte Carlo Experimentation in Econometrics, Version 6.01, Institute of Economics and Statistics and Nuffield College, University of Oxford, Oxford.

Hendry, D. F., A. J. Neale, and F. Srba (1988) "Econometric Analysis of Small Linear Systems Using PC-FIML", Journal of Econometrics, 38, 1/2, 203-226.

Hendry, D. F., and B. Nielsen (2007) Econometric Modeling: A Likelihood Approach, Princeton University Press, Princeton.

Hendry, D. F., A. Pagan, and J. D. Sargan (1984) "Dynamic Specification", Chapter 18 in Z. Griliches and M. D. Intriligator (eds.) Handbook of Econometrics, Volume 2, NorthHolland, Amsterdam, 1023-1100.

Hendry, D. F., and M. H. Pesaran (eds.) (2001) Special Issue in Memory of John Denis Sargan 1924-1996: Studies in Empirical Macroeconometrics, Special Issue, Journal of Applied Econometrics, 16, 3, May-June.

Hendry, D. F., and F. Pretis (2013) "Anthropogenic Influences on Atmospheric $\mathrm{CO}_{2}$ ", Chapter 12 in R. Fouquet (ed.) Handbook on Energy and Climate Change, Edward Elgar, Cheltenham, 287-326.

Hendry, D. F., and J.-F. Richard (1982) "On the Formulation of Empirical Models in Dynamic Econometrics", Journal of Econometrics, 20, 1, 3-33.

Hendry, D. F., and J.-F. Richard (1983) "The Econometric Analysis of Economic Time Series", International Statistical Review, 51, 2, 111-148 (with discussion).

Hendry, D. F., and N. Shephard (eds.) (1997) Cointegration and Dynamics in Economics, Special Issue, Journal of Econometrics, 80, 2, October.

Hendry, D. F., and F. Srba (1977) "The Properties of Autoregressive Instrumental Variables Estimators in Dynamic Systems", Econometrica, 45, 4, 969-990.

Hendry, D. F., and F. Srba (1980) "AUTOREG: A Computer Program Library for Dynamic Econometric Models with Autoregressive Errors", Journal of Econometrics, 12, 1, 85102.

Hendry, D. F., and T. von Ungern-Sternberg (1981) "Liquidity and Inflation Effects on Consumers' Expenditure", Chapter 9 in A. S. Deaton (ed.) Essays in the Theory and Measurement of Consumer Behaviour: In Honour of Sir Richard Stone, Cambridge University Press, Cambridge, 237-260.

Hendry, D. F., and K. F. Wallis (eds.) (1984) Econometrics and Quantitative Economics, Basil Blackwell, Oxford.

Martinez, A. B., J. L. Castle, and D. F. Hendry (2021) "Smooth Robust Multi-horizon Forecasts", Economics Discussion Paper No. 2021-W01, Nuffield College, University of Oxford, Oxford; Advances in Econometrics, 44, forthcoming.

Mizon, G. E., and D. F. Hendry (1980) "An Empirical Application and Monte Carlo Analysis of Tests of Dynamic Specification", Review of Economic Studies, 47, 1, 21-45.

Pretis, F., and D. F. Hendry (2013) "Comment on 'Polynomial Cointegration Tests of Anthropogenic Impact on Global Warming' by Beenstock et al. (2012) - Some Hazards in Econometric Modelling of Climate Change", Earth System Dynamics, 4, 2, 375-384. 
Pretis, F., L. Schneider, J. E. Smerdon, and D. F. Hendry (2016) "Detecting Volcanic Eruptions in Temperature Reconstructions by Designed Break-indicator Saturation", Journal of Economic Surveys, 30, 3, 403-429.

\section{Other Cited Works}

Abadir, K. M., W. Distaso, and F. Žikeš (2014) "Design-free Estimation of Variance Matrices", Journal of Econometrics, 181, 2, 165-180.

Anderson, T. W. (1962) "The Choice of the Degree of a Polynomial Regression as a Multiple Decision Problem", Annals of Mathematical Statistics, 33, 1, 255-265.

Andrews, D. W. K. (1993) "Tests for Parameter Instability and Structural Change with Unknown Change Point", Econometrica, 61, 4, 821-856.

Artis, M. J., A. Banerjee, and M. Marcellino (2005) "Factor Forecasts for the UK", Journal of Forecasting, 24, 4, 279-298.

Attfield, C. L. F., D. Demery, and N. W. Duck (1995) "Estimating the UK Demand for Money Function: A Test of Two Approaches", Mimeo, Department of Economics, University of Bristol, Bristol, England, November.

Bai, J., and P. Perron (1998) "Estimating and Testing Linear Models with Multiple Structural Changes", Econometrica, 66, 1, 47-78.

Bårdsen, G., Ø. Eitrheim, E. S. Jansen, and R. Nymoen (2005) The Econometrics of Macroeconomic Modelling, Oxford University Press, Oxford.

Barendse, S., and A. J. Patton (2019) "Comparing Predictive Accuracy in the Presence of a Loss Function Shape Parameter", Discussion Paper No. 909, Department of Economics, University of Oxford, Oxford, November.

Bates, J. M., and C. W. J. Granger (1969) "The Combination of Forecasts", Operational Research Quarterly, 20, 451-468.

Baumol, W. J. (1952) "The Transactions Demand for Cash: An Inventory Theoretic Approach", Quarterly Journal of Economics, 66, 4, 545-556.

Birchenhall, C. R., H. Jessen, D. R. Osborn, and P. Simpson (1999) "Predicting U.S. Business-cycle Regimes", Journal of Business and Economic Statistics, 17, 3, 313-323.

Box, G. E. P., and G. M. Jenkins (1970) Time Series Analysis: Forecasting and Control, Holden-Day, San Francisco.

Campos, J., and N. R. Ericsson (1999) "Constructive Data Mining: Modeling Consumers' Expenditure in Venezuela", Econometrics Journal, 2, 2, 226-240.

Castle, J. L., and N. Shephard (eds.) (2009) The Methodology and Practice of Econometrics: A Festschrift in Honour of David F. Hendry, Oxford University Press, Oxford.

Chan, N. H., and C. Z. Wei (1988) "Limiting Distributions of Least Squares Estimates of Unstable Autoregressive Processes", Annals of Statistics, 16, 1, 367-401.

Chow, G. C. (1960) "Tests of Equality Between Sets of Coefficients in Two Linear Regressions", Econometrica, 28, 3, 591-605.

Coghlan, R. T. (1978) "A Transactions Demand for Money", Bank of England Quarterly Bulletin, 18, 1, 48-60.

Cooper, J. P., and C. R. Nelson (1975) "The Ex Ante Prediction Performance of the St. Louis and FRB-MIT-PENN Econometric Models and Some Results on Composite Predictors", Journal of Money, Credit, and Banking, 7, 1, 1-32.

Courakis, A. S. (1978) "Serial Correlation and a Bank of England Study of the Demand for Money: An Exercise in Measurement Without Theory", Economic Journal, 88, 351, $537-548$. 
Deaton, A. S. (1977) "Involuntary Saving Through Unanticipated Inflation", American Economic Review, 67, 5, 899-910.

Doornik, J. A. (2001) Ox 3.0: An Object-oriented Matrix Programing Language, Timberlake Consultants Press, London.

Doornik, J. A. (2008) "Encompassing and Automatic Model Selection", Oxford Bulletin of Economics and Statistics, 70, supplement, 915-925.

Doornik, J. A. (2009) "Autometrics", Chapter 4 in J. L. Castle and N. Shephard (eds.) The Methodology and Practice of Econometrics: A Festschrift in Honour of David F. Hendry, Oxford University Press, Oxford, 88-121.

Eitrheim, Ø., Т. A. Husebø, and R. Nymoen (1999) "Equilibrium-correction Versus Differencing in Macroeconometric Forecasting", Economic Modeling, 16, 4, 515-554.

Elliott, G., C. W. J. Granger, and A. Timmermann (eds.) (2006) Handbook of Economic Forecasting, Volume 1, Elsevier, Amsterdam.

Engle, R. F., and C. W. J. Granger (1987) "Co-integration and Error Correction: Representation, Estimation, and Testing", Econometrica, 55, 2, 251-276.

Engle, R. F., and B. S. Yoo (1987) "Forecasting and Testing in Co-integrated Systems", Journal of Econometrics, 35, 1, 143-159.

Ericsson, N. R. (2004) "The ET Interview: Professor David F. Hendry", Econometric Theory, 20, 4, 743-804.

Ericsson, N. R. (2008) "Comment on 'Economic Forecasting in a Changing World' (by Michael Clements and David Hendry)", Capitalism and Society, 3, 2, 2, 1-16.

Ericsson, N. R. (2016) "Eliciting GDP Forecasts from the FOMC's Minutes Around the Financial Crisis", International Journal of Forecasting, 32, 2, 571-583.

Ericsson, N. R. (2017) "Economic Forecasting in Theory and Practice: An Interview with David F. Hendry", International Journal of Forecasting, 33, 2, 523-542.

Ericsson, N. R. (ed.) (2021) Celebrated Econometrician: David F. Hendry, Special Issue, Econometrics, forthcoming.

Escribano, A. (1985) "Non-linear Error-correction: The Case of Money Demand in the U.K. (1878-1970)", Mimeo, University of California at San Diego, La Jolla, California, December.

Escribano, A. (2004) "Nonlinear Error Correction: The Case of Money Demand in the United Kingdom (1878-2000)", Macroeconomic Dynamics, 8, 1, 76-116.

Faust, J., and C. H. Whiteman (1997) "General-to-specific Procedures for Fitting a Data-admissible, Theory-inspired, Congruent, Parsimonious, Encompassing, Weaklyexogenous, Identified, Structural Model to the DGP: A Translation and Critique", Carnegie-Rochester Conference Series on Public Policy, 47, December, 121-161.

Forni, M., M. Hallin, M. Lippi, and L. Reichlin (2001) "Coincident and Leading Indicators for the Euro Area", Economic Journal, 111, 471, C62-C85.

Friedman, M., and A. J. Schwartz (1982) Monetary Trends in the United States and the United Kingdom: Their Relation to Income, Prices, and Interest Rates, 1867-1975, University of Chicago Press, Chicago.

Gilbert, C. L. (1986) "Professor Hendry's Econometric Methodology", Oxford Bulletin of Economics and Statistics, 48, 3, 283-307.

Goldfeld, S. M. (1976) "The Case of the Missing Money", Brookings Papers on Economic Activity, 1976, 3, 683-730 (with discussion).

Goodhart, C. A. E. (1982) "Monetary Trends in the United States and the United Kingdom: A British Review", Journal of Economic Literature, 20, 4, 1540-1551.

Granger, C. W. J. (1981) "Some Properties of Time Series Data and Their Use in Econometric Model Specification", Journal of Econometrics, 16, 1, 121-130. 
Granger, C. W. J. (1986) "Developments in the Study of Cointegrated Economic Variables", Oxford Bulletin of Economics and Statistics, 48, 3, 213-228.

Granger, C. W. J. (2001) "Evaluation of Forecasts", Chapter 6 in D. F. Hendry and N. R. Ericsson (eds.) Understanding Economic Forecasts, MIT Press, Cambridge, Massachusetts, 93-103.

Granger, C. W. J. (2004) "Time Series Analysis, Cointegration, and Applications", in T. Frängsmyr (ed.) The Nobel Prizes 2003, Almqvist and Wiksell International, Stockholm, 360-366.

Granger, C. W. J., and P. Newbold (1977) "The Time Series Approach to Econometric Model Building", in C. A. Sims (ed.) New Methods in Business Cycle Research: Proceedings from a Conference, Federal Reserve Bank of Minneapolis, Minneapolis, Minnesota, 7-21 (with discussion).

Granger, C. W. J., and A. A. Weiss (1983) "Time Series Analysis of Error-correction Models", in S. Karlin, T. Amemiya, and L. A. Goodman (eds.) Studies in Econometrics, Time Series, and Multivariate Statistics: In Honor of Theodore W. Anderson, Academic Press, New York, 255-278.

Hacche, G. (1974) "The Demand for Money in the United Kingdom: Experience Since 1971", Bank of England Quarterly Bulletin, 14, 3, 284-305.

Hall, R. E. (1978) "Stochastic Implications of the Life Cycle-Permanent Income Hypothesis: Theory and Evidence", Journal of Political Economy, 86, 6, 971-987.

Hatch, N. (2001) "Modeling and Forecasting at the Bank of England", Chapter 8 in D. F. Hendry and N. R. Ericsson (eds.) Understanding Economic Forecasts, MIT Press, Cambridge, Massachusetts, 124-148.

Hoover, K. D., and S. J. Perez (1999) "Data Mining Reconsidered: Encompassing and the General-to-specific Approach to Specification Search", Econometrics Journal, 2, 2, 167-191 (with discussion).

Johansen, S. (1988) "Statistical Analysis of Cointegration Vectors", Journal of Economic Dynamics and Control, 12, 2/3, 231-254.

Johansen, S. (1995) Likelihood-based Inference in Cointegrated Vector Autoregressive Models, Oxford University Press, Oxford.

Johansen, S., and K. Juselius (1990) "Maximum Likelihood Estimation and Inference on Cointegration-With Applications to the Demand for Money", Oxford Bulletin of Economics and Statistics, 52, 2, 169-210.

Johansen, S., and B. Nielsen (2009) "An Analysis of the Indicator Saturation Estimator as a Robust Regression Estimator", Chapter 1 in J. L. Castle and N. Shephard (eds.) The Methodology and Practice of Econometrics: A Festschrift in Honour of David F. Hendry, Oxford University Press, Oxford, 1-36.

Johansen, S., and B. Nielsen (2013) "Outlier Detection in Regression Using an Iterated One-step Approximation to the Huber-skip Estimator", Econometrics, 1, 1, 53-70.

Johansen, S., and B. Nielsen (2016) "Asymptotic Theory of Outlier Detection Algorithms for Linear Time Series Regression Models", Scandinavian Journal of Statistics, 43, 2, 321-381 (with discussion and rejoinder).

Juselius, K. (2006) The Cointegrated VAR Model: Methodology and Applications, Oxford University Press, Oxford.

Kiviet, J. F. (1986) "On the Rigour of Some Misspecification Tests for Modelling Dynamic Relationships", Review of Economic Studies, 53, 2, 241-261.

Klein, L. R. (1950) Economic Fluctuations in the United States, 1921-1941 (Cowles Commission Monograph No. 11), John Wiley, New York.

Klein, L. R. (1971) An Essay on the Theory of Economic Prediction, Markham Publishing Company, Chicago. 
Longbottom, A., and S. Holly (1985) "Econometric Methodology and Monetarism: Professor Friedman and Professor Hendry on the Demand for Money", Discussion Paper No. 131, London Business School, London, February.

Magnus, J. R., and M. S. Morgan (eds.) (1999) Methodology and Tacit Knowledge: Two Experiments in Econometrics, John Wiley and Sons, Chichester.

Makridakis, S., and M. Hibon (2000) "The M3-Competition: Results, Conclusions and Implications", International Journal of Forecasting, 16, 4, 451-476.

Martinez, A. B. (2020a) "Forecast Accuracy Matters for Hurricane Damage", Econometrics, $8,2,18,1-24$.

Martinez, A. B. (2020b) "Improving Normalized Hurricane Damages", Nature Sustainability, 2020, https://doi.org/10.1038/s41893-020-0550-5.

Mazzi, G. L., and D. Ladiray (eds.) (2017) Handbook on Rapid Estimates: 2017 Edition, European Union, Luxembourg.

Mills, T. C. (2011) "Bradford Smith: An Econometrician Decades Ahead of His Time", Oxford Bulletin of Economics and Statistics, 73, 2, 276-285.

Mizon, G. E. (1977) "Inferential Procedures in Nonlinear Models: An Application in a UK Industrial Cross Section Study of Factor Substitution and Returns to Scale", Econometrica, 45, 5, 1221-1242.

Mizon, G. E. (1995) "Progressive Modeling of Macroeconomic Time Series: The LSE Methodology", Chapter 4 in K. D. Hoover (ed.) Macroeconometrics: Developments, Tensions, and Prospects, Kluwer Academic Publishers, Boston, Massachusetts, 107-170 (with discussion).

Nelson, C. R. (1972) "The Prediction Performance of the FRB-MIT-PENN Model of the U.S. Economy", American Economic Review, 62, 5, 902-917.

Osborn, D. R. (1988) "Seasonality and Habit Persistence in a Life Cycle Model of Consumption", Journal of Applied Econometrics, 3, 4, 255-266.

Osborn, D. R. (1991) "The Implications of Periodically Varying Coefficients for Seasonal Time-series Processes", Journal of Econometrics, 48, 3, 373-384.

Phillips, A. W. (1954) "Stabilisation Policy in a Closed Economy", Economic Journal, 64, $254,290-323$.

Phillips, A. W. (1957) "Stabilisation Policy and the Time-forms of Lagged Responses", Economic Journal, 67, 266, 265-277.

Phillips, P. C. B. (1986) "Understanding Spurious Regressions in Econometrics", Journal of Econometrics, 33, 3, 311-340.

Phillips, P. C. B. (1987) "Time Series Regression with a Unit Root", Econometrica, 55, 2, 277-301.

Phillips, P. C. B. (1995) "Automated Forecasts of Asia-Pacific Economic Activity", AsiaPacific Economic Review, 1, 1, 92-102.

Phillips, P. C. B. (1996) "Econometric Model Determination", Econometrica, 64, 4, 763812.

Pretis, F. (2020) "Econometric Modelling of Climate Systems: The Equivalence of Energy Balance Models and Cointegrated Vector Autoregressions", Journal of Econometrics, 214, 1, 256-273.

Raven, J., T. Hoehn, D. Lancefield, and B. Robinson (2004) Economic Analysis of the TV Advertising Market, PricewaterhouseCoopers LLP, London, December (available from www.ofcom.org.uk/__data/assets/pdf_file/0018/23913/tvadvmarket.pdf).

Richard, J.-F., and W. Zhang (1996) "Econometric Modelling of UK House Prices Using Accelerated Importance Sampling", Oxford Bulletin of Economics and Statistics, 58, 4, 601-613. 
Rose, A. K. (1985) "An Alternative Approach to the American Demand for Money", Journal of Money, Credit, and Banking, 17, 4, Part 1, 439-455.

Salkever, D. S. (1976) "The Use of Dummy Variables to Compute Predictions, Prediction Errors, and Confidence Intervals", Journal of Econometrics, 4, 4, 393-397.

Sargan, J. D. (1964) "Wages and Prices in the United Kingdom: A Study in Econometric Methodology", in P. E. Hart, G. Mills, and J. K. Whitaker (eds.) Econometric Analysis for National Economic Planning, Volume 16 of Colston Papers, Butterworths, London, 25-54 (with discussion).

Sargan, J. D. (1975) "Asymptotic Theory and Large Models", International Economic Review, 16, 1, 75-91.

Sargan, J. D. (1980) "Some Tests of Dynamic Specification for a Single Equation", Econometrica, 48, 4, 879-897.

Siegert, W. K. (1999) "An Application of Three Econometric Methodologies to the Estimation of the Income Elasticity of Food Demand", Chapter 16 in J. R. Magnus and M. S. Morgan (eds.) Methodology and Tacit Knowledge: Two Experiments in Econometrics, John Wiley and Sons, Chichester, 315-340.

Smith, B. B. (1926) "Combining the Advantages of First-Difference and Deviation-FromTrend Methods of Correlating Time Series", Journal of the American Statistical Association, 21, 153, 55-59.

Stekler, H. O., and H. Symington (2016) "Evaluating Qualitative Forecasts: The FOMC Minutes, 2006-2010", International Journal of Forecasting, 32, 2, 559-570.

Stock, J. H. (1987) "Asymptotic Properties of Least Squares Estimators of Cointegrating Vectors", Econometrica, 55, 5, 1035-1056.

Stock, J. H., and M. W. Watson (2011) "Dynamic Factor Models", Chapter 2 in M. P. Clements and D. F. Hendry (eds.) Oxford Handbook of Economic Forecasting, Oxford University Press, Oxford, 35-59.

Tinbergen, J. (1951) Business Cycles in the United Kingdom, 1870-1914, North-Holland, Amsterdam.

Tobin, J. (1950) "A Statistical Demand Function for Food in the U.S.A.", Journal of the Royal Statistical Society, Series A, 113, 2, 113-141.

Tobin, J. (1956) "The Interest Elasticity of Transactions Demand for Cash", Review of Economics and Statistics, 38, 3, 241-247.

Treasury and Civil Service Committee (1991a) Memoranda on Official Economic Forecasting, Session 1990-91, House of Commons, Her Majesty's Stationery Office, London (2 volumes).

Treasury and Civil Service Committee (1991b) Official Economic Forecasting, Minutes of Evidence, Session 1990-91, House of Commons, Her Majesty's Stationery Office, London.

Trivedi, P. K. (1970) "The Relation Between the Order-Delivery Lag and the Rate of Capacity Utilization in the Engineering Industry in the United Kingdom, 1958-1967", Economica, 37, 145, 54-67.

Wallis, K. F. (1993) "On the Limitations of Comparing Mean Square Forecast Errors: Comment", Journal of Forecasting, 12, 8, 663-666.

White, H. (1990) "A Consistent Model Selection Procedure Based on m-Testing", Chapter 16 in C. W. J. Granger (ed.) Modelling Economic Series: Readings in Econometric Methodology, Oxford University Press, Oxford, 369-383.

Yule, G. U. (1926) "Why Do We Sometimes Get Nonsense Correlations Between Time Series?-A Study in Sampling and the Nature of Time Series", Journal of the Royal Statistical Society, 89, 1, 1-64. 